\title{
Estimating surface mass balance patterns from unoccupied aerial vehicle measurements in the ablation area of the Morteratsch-Pers glacier complex (Switzerland)
}

\author{
Lander Van Tricht ${ }^{1}$, Philippe Huybrechts ${ }^{1}$, Jonas Van Breedam ${ }^{1}$, Alexander Vanhulle ${ }^{1}$, Kristof Van Oost ${ }^{2}$, and \\ Harry Zekollari ${ }^{3}$ \\ ${ }^{1}$ Earth System Science \& Departement Geografie, Vrije Universiteit Brussel, Brussels, Belgium \\ ${ }^{2}$ Georges Lemaitre Center for Earth \& Climate Research, Earth and Life Institute, Université catholique de Louvain, \\ Louvain-la-Neuve, Belgium \\ ${ }^{3}$ Department of Geoscience and Remote Sensing, Delft University of Technology, Delft, the Netherlands
}

Correspondence: Lander Van Tricht (lander.van.tricht@ vub.be)

Received: 15 March 2021 - Discussion started: 29 March 2021

Revised: 12 August 2021 - Accepted: 16 August 2021 - Published: 14 September 2021

\begin{abstract}
The surface mass balance (SMB) of a glacier provides the link between the glacier and the local climate. For this reason, it is intensively studied and monitored. However, major efforts are required to determine the point SMB at a sufficient number of locations to capture the heterogeneity of the SMB pattern. Furthermore, because of the timeconsuming and costly nature of these measurements, detailed SMB measurements are carried out on only a limited number of glaciers. In this study, we investigate how to accurately determine the SMB in the ablation zone of Vadret da Morteratsch and Vadret Pers (Engadin, Switzerland) using the continuity equation method, based on the expression of conservation of mass for glacier flow with constant density. An elaborate dataset (spanning the 2017-2020 period) of high-resolution data derived from unoccupied aerial vehicle (UAV) measurements (surface elevation changes and surface velocities) is combined with reconstructed ice thickness fields (based on radar measurements). To determine the performance of the method, we compare modelled SMB with measured SMB values at the position of stakes. Our results indicate that with annual UAV surveys, it is possible to obtain SMB estimates with a mean absolute error smaller than $0.5 \mathrm{~m}$ of ice equivalent per year. Yet, our study demonstrates that to obtain these accuracies, it is necessary to consider the ice flow over spatial scales of several times the local ice thickness, accomplished in this study by applying an exponential decay filter. Furthermore, our study highlights the crucial im-
\end{abstract}

portance of the ice thickness, which must be sufficiently well known in order to accurately apply the method. The latter currently seems to complicate the application of the continuity equation method to derive detailed SMB patterns on regional to global scales.

\section{Introduction}

The surface mass balance of a glacier is determined by the processes adding mass to the surface (e.g. snowfall, freezing rain) and those removing mass from the surface (e.g. snow and ice melt, sublimation). These processes are strongly driven by the energy budget and precipitation over the glacier. As a result of increased global mean temperatures, surface mass balances (SMBs) are becoming increasingly negative, leading to an unprecedented shrinkage of glaciers during the last decade (Zemp et al., 2019; Wouters et al., 2019). Because of the direct link with the local climatic signal, it is crucial to determine the surface mass balance distribution for monitoring, understanding and modelling the glacier's reaction to climate change. Traditionally, a stake and snow pit network is used to determine the SMB followed by an interpolation and extrapolation to obtain the glacier mean specific mass balance (Braithwaite, 2002). This can result in large errors for glaciers where the heterogeneity of the SMB cannot be captured sufficiently by the available mea- 
surements (Zemp et al., 2013). Further, because of the timeconsuming and costly nature of these measurements, detailed SMB measurements are carried out on only a limited number of glaciers.

Geodetic methods provide an alternative and have been applied for many decades in numerous studies to monitor mass balances for individual glaciers at local to regional scales (e.g. Brun et al., 2017; Davaze et al., 2020; Sommer et al., 2020). These methods all involve comparing digital elevation models (DEMs), mainly created using airborne and satellite data, over a given period to determine local elevation changes. These local elevation changes result from an interaction between mass balance and ice flow processes and therefore do not allow the mass balance distribution to be directly determined over glaciers (Berthier and Vincent, 2012). However, having such a mass balance distribution over glaciers is of large interest as this can be used to accurately calibrate mass balance models used in large-scale glacier modelling efforts to allow for example for an accurate calibration of mass balance gradients (Zekollari and Huybrechts, 2018; Marzeion et al., 2020).

Several studies have attempted to determine patterns of SMB from surface elevation changes by implementing either mass continuity, a kinematic boundary condition at the surface or 3D ice flow modelling (Kääb and Funk, 1999; Gudmundsson and Bauder, 1999; Hubbard et al., 2000; Reeh et al., 2002; Nuimura et al., 2011; Vincent et al., 2016; Brun et al., 2018; Bisset et al., 2020; Wagnon et al., 2021; Miles et al., 2021). In essence, these are all based on the principle of combining surface elevation changes with the ice flux divergence. While the former can be measured directly, the latter is calculated by combining various types of measurements. Most previous studies stumbled on the necessity, resulting from the discretisation of ice flow processes and spatial resolution of the data, to smooth the input data or the ice flux divergence or to resample to much lower resolutions of several hundreds of metres. Other studies used cross-sectional flux gates to simplify the problem and calculate a uniform flux divergence across a glacier area downstream of such a flux gate or between two flux gates (Berthier and Vincent, 2012; Vincent et al., 2016). Further, a recurring drawback in previous studies attempting to detect local and small-scale variations in the SMB was the lack of satellite observations with a sufficiently high spatial and temporal resolution (Ryan et al., 2015). However, with the emergence of unoccupied aerial vehicles (UAVs), it turned out to be possible to detect smallscale variations at unprecedented centimetre resolution. Accordingly, several studies have been conducted to derive surface velocities from repeated UAV surveys (Immerzeel et al., 2014; Ryan et al., 2015; Kraaijenbrink et al., 2016; Rossini et al., 2018; Benoit et al., 2019), while other studies focussed on the generation of surface elevation changes from multiple UAV surveys and the comparison with stake measurements (Groos et al., 2019; Yang et al., 2020). Recently, a study has also attempted to determine the SMB at the location of indi- vidual ablation stakes using an UAV and with measured vertical velocities (Vincent et al., 2021). However, to our knowledge, no research has yet been carried out to derive a transferable method to determine the SMB distribution over an entire ablation zone using multiannual UAV measurements. Furthermore, the optimal ways to calculate the ice flux divergence and how to represent the spatial scales over which ice flow occurs without resampling to a much lower resolution remain a topic of discussion.

The aim of this study consists of deriving and applying a method to determine the SMB in the entire ablation zone of two glaciers by combining UAV-acquired 3D data and ice thickness measurements through the continuity equation method. We pay particular attention to the spatial scales that need to be considered in this framework and how these influence the modelled SMB. The performance is evaluated through an in-depth comparison with measured SMB values at stakes. To allow the method to be applied for other glaciers, with different data availability, we also perform a comprehensive sensitivity analysis, from which we determine which data are crucial in the application of the method and their accuracy.

\section{Study area and fieldwork}

The current study focuses on the Morteratsch-Pers glacier complex situated in the Bernina massif in the south-eastern part of Switzerland (European Alps) (Fig. 1). Vadret da Morteratsch, with a current length of approximately $6 \mathrm{~km}$, is the main glacier and flows from the south to the north. Vadret Pers, which flows towards Vadret da Morteratsch from the south-east, became a separate glacier in 2015, when the glaciers disconnected (Zekollari and Huybrechts, 2018). At present, the two glaciers cover an area of about $15 \mathrm{~km}^{2}$ with a volume of ca. $1 \mathrm{~km}^{3}$, making it the largest continuous ice area in the Bernina region. Vadret da Morteratsch reached its maximum Little Ice Age (LIA) extent between 1860 and 1865 (Zekollari et al., 2014). Since 1878, the glacier front has retreated more than $3 \mathrm{~km}$ and is nowadays located at an altitude of $2200 \mathrm{~m}$ above sea level (a.s.1.). The peculiar shape of the front of the Vadret da Morteratsch (see Fig. 1) is caused by a combination of a large amount of debris on the western side that kept the ice below more insulated during the past years and shading effects from the surrounding mountains. Since the 2000s, the front of the glacier has retreated significantly, but a large area of stagnant ice remained protruded to the north on the western side of the valley (Fig. 1). The upper parts of the glacier complex reach $4000 \mathrm{~m}$ a.s.l., originating at peaks such as Piz Bernina and Bellavista (Fig. 1). The glacier complex has been studied and monitored intensively with SMB stake measurements performed annually at the end of the ablation season since 2001 (Zekollari and Huybrechts, 2018). In addition, the geodetic mass balance of the 1980-2010 period was determined to be between -0.7 and 


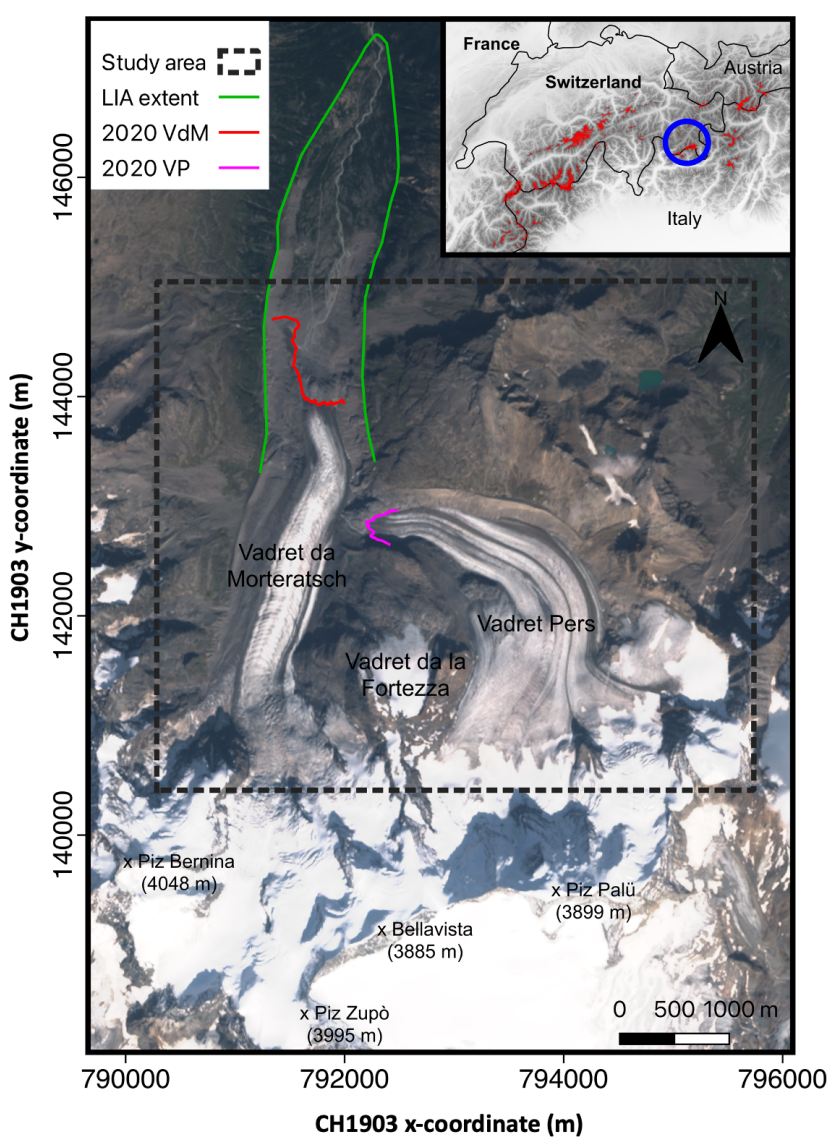

Figure 1. Map of the Morteratsch-Pers glacier complex in southeastern Switzerland. The different coloured lines represent the extent of the glacier(s) at the end of the Little Ice Age (LIA; 18601865) and in 2020. The background image is a Sentinel-2 true colour composite satellite image from 13 September 2020. The highest mountains are labelled and indicated with a black cross. The inset shows a DEM of the Shuttle Radar Topography Mission (SRTM) and boundaries of the countries of the central and western European Alps. The areas indicated with a red colour are glaciers according to the Randolph Glacier Inventory (RGI) version 6. The location of the Morteratsch-Pers glacier complex is indicated with a blue circle.

$-0.8 \mathrm{~m}$ of water equivalent per year (Fischer et al., 2015). The SMB stake measurements served to calibrate a mass balance model (Nemec et al., 2009) which was coupled to a higher-order ice flow model to simulate the future evolution of the glacier complex (Zekollari et al., 2014) and to study its response time (Zekollari and Huybrechts, 2015). Furthermore, the ice thickness in the ablation area has previously been measured twice (Zekollari et al., 2013; Langhammer et al., 2019).

\subsection{UAV surveys}

Between 2017 and 2020, we conducted annual UAV surveys at the end of the ablation season (late September). Hence,
Table 1. Technical details and characteristics of the UAV flights.

\begin{tabular}{ll}
\hline Setting or characteristic & Value \\
\hline Flight height above the surface & On average $180 \mathrm{~m}$ \\
Ground resolution & $0.05-0.09 \mathrm{~m}$ \\
View angle & $90^{\circ}$ \\
Flight speed & $5 \mathrm{~m} \mathrm{~s}^{-1}$ \\
Capture interval & $4 \mathrm{~s}$ \\
Frontal overlap & $90 \%$ \\
Side overlap & $70 \%$ \\
Survey area (2020) & $14.5 \mathrm{~km}^{2}$ \\
Number of images (2020) & 8107 \\
Average number of key points per image & $65000-70000$ \\
Average matched key points per image & $32000-36000$ \\
\hline
\end{tabular}

the focus in this research is on 3 mass balance years (20172018, 2018-2019 and 2019-2020). In 2017, above-normal snow cover and severe weather conditions prevented drone mapping on the upper parts of the ablation area of Vadret Pers $(>2800 \mathrm{~m})$ due to inadequate visual content for accurate key point detection (Gindraux et al., 2017) and the inability to distribute control points. This resulted in a smaller study area in 2017-2018. The observations consist of images acquired by repeated UAV surveys with a DJI Phantom 4 Pro (P4PRO) (in 2017, 2018 and 2019) and a DJI Phantom 4 RTK (P4RTK) (in 2020) quadcopter, both equipped with a 20-megapixel camera. For flight planning and UAV piloting, DJI GS Pro was used. The flight plans were designed to limit the variation in ground sampling distance (GSD) by flying parallel to the main surface slope and by subdividing the study area into smaller sections. We ensured in every case sufficient overlap between the different flight plans so that they could be easily attached to each other afterwards. Additional technical details of the flights are given in Table 1. The different flights within one field campaign were performed on multiple days. However, because of the short fieldwork periods (4-6d), the difference between the SMB measurements and surface elevation changes caused by not surveying simultaneously is estimated to be at most up to $10 \mathrm{~cm}$, which is within the uncertainty bounds of the measurements. Therefore, no correction was applied for the difference in acquisition dates.

To ensure sufficient horizontal and vertical accuracy, ground control points (GCPs) were distributed over the area of interest (see Fig. 2). The GCPs, plastic orange squares of $40 \times 40 \mathrm{~cm}$, were measured with a Trimble $7 \mathrm{GeoXH}$ RTK GPS (horizontal average accuracy of $10-20 \mathrm{~cm}$, vertical average accuracy of $20-30 \mathrm{~cm}$ ) by relying on the Swiss Positioning Service (swipos) GIS/GEO. The GCPs were spread over different locations on the glacier following density and distribution guidelines from the literature (Tahar et al., 2012; Goldstein et al., 2015; Long et al., 2016; Tonkin and Midgley, 2016; Gindraux et al., 2017). We ensured homogeneous distribution in almost every case, except where crevasses, 
moulins or a fresh layer of snow (especially in 2017) impeded this, with an average density of $10-20 \mathrm{GCPs} \mathrm{km}^{-2}$. Specific attention was paid to the distribution of GCPs in the overlapping areas of the different flight areas in order to be able to georeference two neighbouring flight areas with the same points. In 2020, a smaller number of GCPs were placed because the P4RTK can achieve centimetre-level accuracy without a large number of GCPs as a result of an onboard differential GPS system (Zhang et al., 2019; Kienholz et al., 2020). Each year, some of the GCPs were not used for the georeferencing process but as a ground validation point (GVP) to assess the quality of the reconstructed digital surface model (DSM).

\subsection{In situ surface mass balance data}

A total of 287 annual mass balance stake measurements (158 on Morteratsch, 129 on Pers) were performed between 2001 and 2020 in the ablation area of the glacier complex, with an average number of 15 stakes in each year. All the stakes were located between 2100 and $2600 \mathrm{~m}$ a.s.l. on the Morteratsch glacier's ablation tongue and between 2450 and $3050 \mathrm{~m}$ a.s.l. (approximately the equilibrium line altitude, ELA) on Vadret Pers. Zekollari and Huybrechts (2018) summarised these measurements and found the SMB rate on Pers glacier to be significantly lower $(-2.1$ to $-2.5 \mathrm{~m}$ of ice equivalent (m i.e.) $\mathrm{yr}^{-1}$ ) compared to Vadret da Morteratsch at similar elevation. This has been mainly attributed to differences in orientation and the associated daily insolation cycle over the two glaciers. For the period of concern in this study (20172020), SMB measurements from 16 individual stakes (8 on each glacier) are available for every year on the debris-free part of the ablation areas (Fig. 2). The stakes were measured and replaced if necessary annually at the end of each ablation season, during the UAV surveys.

\subsection{Ice thickness data}

To calculate the local ice volume flux divergence (see Sect. 3.4), a distribution of the ice thickness is required. There are two published datasets of the ice thickness of the Morteratsch-Pers glacier complex, derived from radar measurements (especially in the ablation area) and modelling (especially in the accumulation area). The first one is the dataset of Zekollari et al. (2013), hereafter referred to as THIZ. This distribution was reconstructed by combining measured ice thicknesses $(\sim 30$ ground-borne ground penetrating radar (GPR) profiles in the early 2000s) with different modelling constraints. The second ice thickness distribution is the dataset of Langhammer et al. (2019), hereafter referred to as THIL. This distribution was produced by combining measured ice thicknesses (41 helicopter-borne GPR profiles with a total of 53247 points measured in 2017) and modelling constraints with the Glacier Thickness Estimation (GlaTE) inversion scheme (Langhammer et al., 2019). We

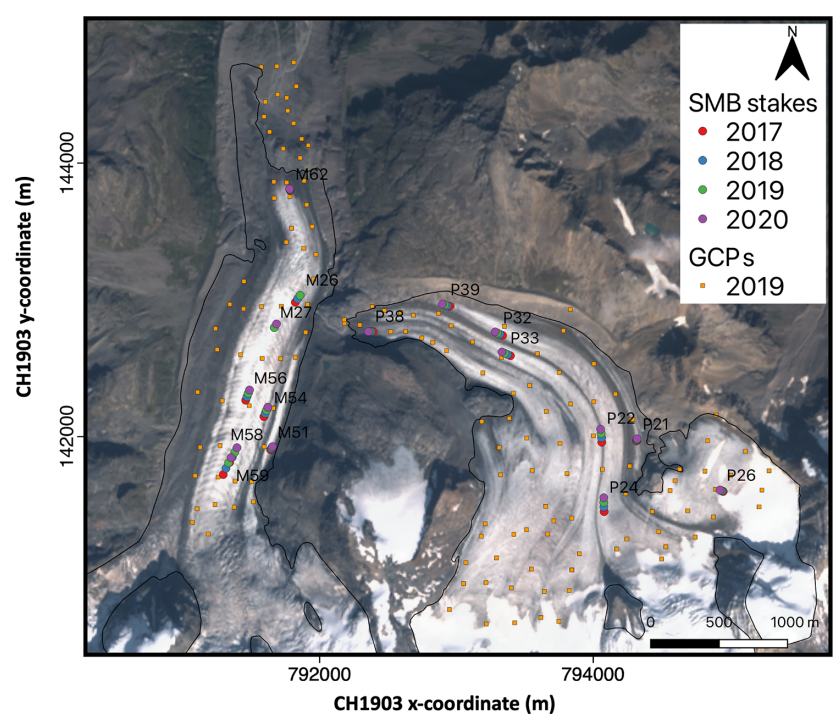

Figure 2. Satellite image of the study area with the location of the measured ablation stakes in 2017, 2018, 2019 and 2020. The GCPs of 2019 are indicated with an orange square. The background image is a Sentinel-2 true colour composite satellite image from 13 September 2020. The different locations of the stakes in 2017 , 2018, 2019 and 2020 show the movement of the stakes with the glacier flow. The labels refer to the stake names as used in the fieldwork programme. In 2019, stake M26, which was located in the middle of a crevasse field, was replaced by stake M27.

correct both datasets for glacier geometry changes to refer to the glacier state in 2018, 2019 and 2020, respectively, by subtracting the amount of local surface lowering. This concerns the local height difference between the UAV-created DSMs of 2018-2019-2020 and the DEM used for the respective ice thickness datasets. The latter are two DEMs provided by SwissTopo. DHM25 is valid for 1991 (used for THIZ), and SwissALTI3D is valid for 2015 (used for THIL).

Although both ice thickness distributions (Fig. 3a and b) have a similar pattern (location of overdeepenings, location of maximum ice thickness), large local differences exist (Fig. 3d). The ice thickness maximum, corrected to represent the ice thickness in 2020, for instance occurs at a similar location but is about $310 \mathrm{~m}$ for THIZ and $250 \mathrm{~m}$ for THIL. This corresponds to a difference of $18 \%-24 \%$, which is, however, still within the error bounds of the datasets. Conversely, there are also certain zones (especially higher up Vadret da Morteratsch) where the difference between the two datasets is about $150 \mathrm{~m}$.

Because of the significant differences between both ice thickness distributions, the choice for a particular distribution has a considerable effect on the calculations in this study. To verify the maximum ice thickness of Vadret da Morteratsch, we measured the ice thickness once again in the thickest region in 2020 (see Fig. 3c) with a Narod radio echo sounding (RES) system, similar to Zekollari et al. (2013) and Van Tricht et al. (2021). We preferred to use a low frequency of 
$5 \mathrm{MHz}$ to limit the amount of attenuation due to disturbances in the glacier such as water inclusions, repeatedly observed during the fieldwork. We found a maximum value of $296 \mathrm{~m}$, which is relatively close to the maximum thickness from the THIZ dataset. We can therefore certainly not ignore this dataset, despite the smaller number of measurements and the older date of creation. Therefore, for further calculations, we decided to use the mean ice thickness from THIZ and THIL at every grid cell, hereafter referred to as THIA (Fig. 3c). The effect of using THIA, as opposed to relying on THIZ or THIL, is examined as a part of the sensitivity analysis (see Sect. 5.1). For the areas where the current elevation is lower than the bedrock inferred from THIZ and THIL and where there is no ice as a result within the current glacier outline, we assume a minimal ice thickness of $5 \mathrm{~m}$ as in Zekollari et al. (2013).

\section{Methods}

\subsection{Continuity equation method}

The continuity equation for glacier flow with constant density (Eq. 1) links the local mass balance (b) and the ice flux divergence per unit width in the local vertical ice column $(\nabla \cdot \boldsymbol{q})$ with local changes in the ice thickness $\left(\frac{\partial H}{\partial t}\right)$, all expressed in $\mathrm{m}$ i.e. $\mathrm{yr}^{-1}$ (see e.g. Hubbard et al., 2000; Berthier and Vincent, 2012).

$$
\frac{\partial H}{\partial t}=b-\nabla \cdot \boldsymbol{q}
$$

Equation (1) shows that the difference between the local mass balance and ice flux divergence must be compensated by a change in local ice thickness. If the bedrock elevation is assumed to be constant, and compaction is negligible, which is the case in the ablation area (with ice throughout the entire column), the local ice thickness $(H)$ in Eq. (1) can be replaced by the elevation of the surface $(h)$. Further, because basal and internal mass balance in the ablation area are predominantly much smaller compared to the surface mass balance $\left(b_{\mathrm{s}}\right)$ (Kaser et al., 2003; Huss et al., 2015), $b$ can be replaced by $b_{\mathrm{s}}$, which after a reorganisation leads to the following expression:

$b_{\mathrm{s}}=\frac{\partial h}{\partial t}+\nabla \cdot \boldsymbol{q}$

By determining the local elevation changes (Sect. 3.2) and the components that make up for the ice flux divergence per unit width (from now on referred to as ice flux divergence; Sect. 3.3-3.4), the SMB pattern can then be derived.

\subsection{DSM generation and surface elevation changes $(\partial h / \partial t)$}

First, all the data from the UAV surveys are used to generate DSMs on a common local coordinate system
(CH1903 + LV95). All the images collected during the UAV surveys are processed into orthophotos and DSMs using the photogrammetry workflow implemented in Pix4D. The accuracy of the reconstructed DSMs is assessed using the GVPs and the stable terrain outside the glacierised areas. Subsequently, surface elevation changes are directly computed from these DSMs by subtracting the DSMs from each other (2018-2017, 2019-2018, 2020-2019). Initially, all the DSMs are generated with a very high resolution of $0.05-$ $0.09 \mathrm{~m}$. But eventually, the surface elevation changes are resampled to $25 \mathrm{~m}$ resolution for further calculations using a block moving-average filter. This corresponds to the resolution of the ice thickness datasets and will therefore be the grid size for all of the following calculations.

A commonly observed feature on surface elevation change maps derived from high-resolution DSMs are alternating positive and negative differences. These are caused by the advection of local glacier topography such as crevasses, moulins, supraglacial melt streams, and large ice or rock boulders (Fig. 4) (Brun et al., 2018; Rounce et al., 2018; Yang et al., 2020). The above-mentioned variations are not caused by reduced or increased melt or accumulation and therefore need to be corrected for ice flow to make a correct SMB estimate.

The different DSMs are treated considering the motion of the ice, following the method applied in e.g. Brun et al. (2018). This method consists of projecting each point on the glacier back to its original position in the previous year, based on the local velocity in the $x$ and $y$ direction and taking into account the vertical displacement produced by flow along the longitudinal slope. The latter is determined by taking the average slope over all the different years for which a DSM was made, smoothed with a Gaussian filter with a 25-pixel kernel size $(50 \mathrm{~m})$.

\subsection{Horizontal surface velocity}

Glacier surface velocities, which are needed to calculate the ice flux divergence (Sect. 3.4) and to flow-correct the surface elevation changes (Sect. 3.2), are computed for the 3 individual mass balance years. Velocity grids are derived by applying the Image GeoRectification And Feature Tracking (ImGRAFT) toolbox, an open-source tool in MATLAB (Messerli and Grinsted, 2015). Specific settings for the template matching of ImGRAFT are the use of the orientation correlation (OC) method and a large search height and search width of $200 \mathrm{~m}$ to guarantee that all possible areas are covered. Instead of using visual image data with variable illumination and snow cover, the feature tracking algorithm is run on hillshades (relief DSMs) of the original DSMs, resampled to a resolution of $2 \mathrm{~m}$ (Messerli and Grinsted, 2015). The latter turned out to improve the correlation success (Rounce et al., 2018).

Velocity maps are computed and corrected for differences in acquisition dates to obtain values in metres per year. Then, 


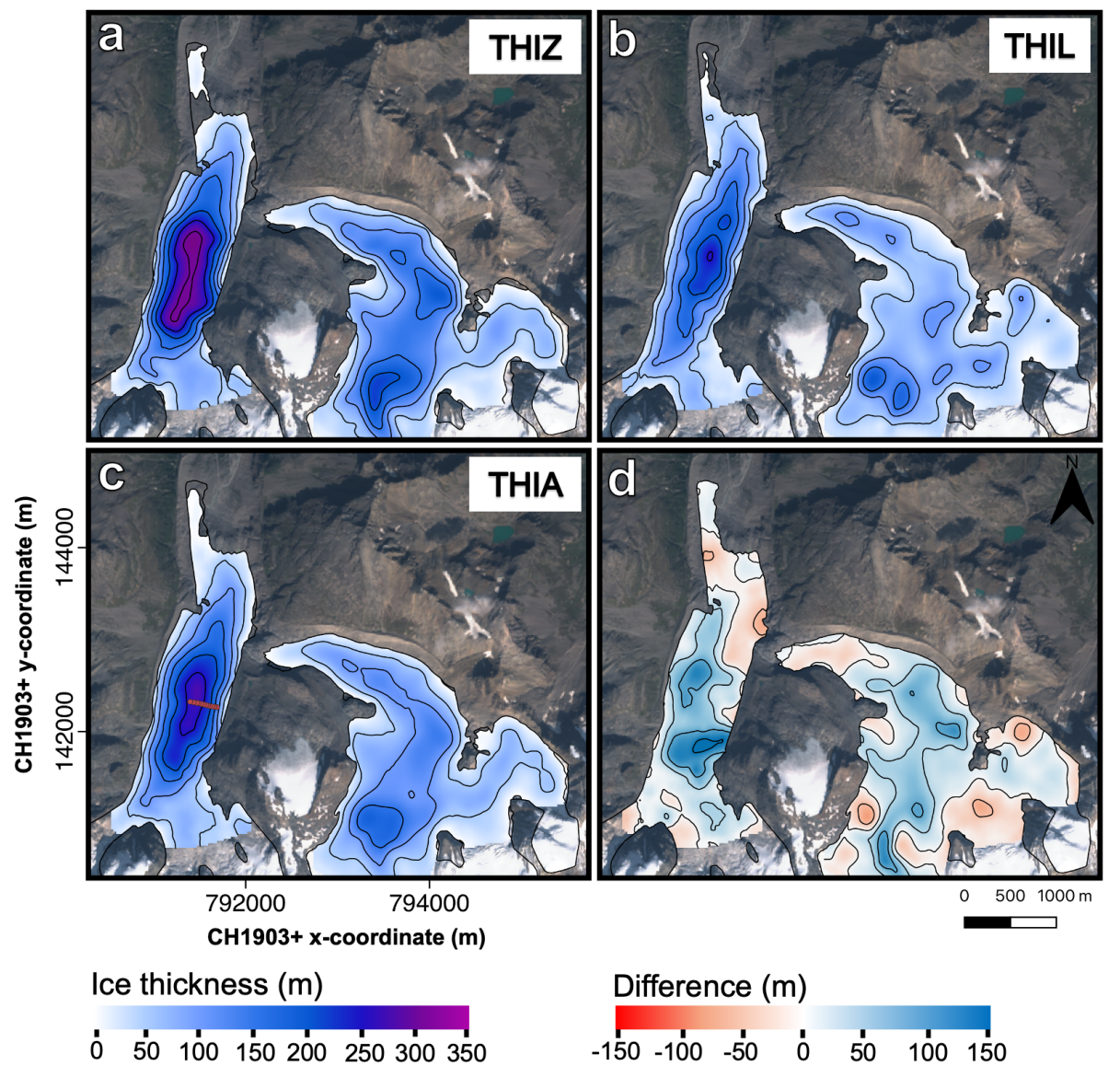

Figure 3. Ice thickness distribution of the ablation area of the Morteratsch-Pers glacier complex in 2020. (a) THIZ (ice thickness distribution of Zekollari et al., 2013), (b) THIL (ice thickness distribution of Langhammer et al., 2019) and (c) THIA (average ice thickness distribution). The difference between THIZ and THIL is shown in panel (d). Contour lines represent $50 \mathrm{~m}$ intervals. Note that at the front of Vadret da Morteratsch and locally at the front of Vadret Pers, the glacier outline is larger than the ice thickness dataset. The current surface elevation of these areas is lower than the bedrock elevation inferred from THIL and THIZ. The locations of the ice thickness measurements of 2020 are added in panel (c) with red circles. The background image is a Sentinel-2 true colour composite satellite image from 13 September 2020.

a series of filters are applied to the output of the crosscorrelation to exclude poorly correlated pixels and those with unrealistic displacements or flow directions (Ruiz et al., 2015). The latter is a common issue for snow-covered areas, debris-covered areas or complex crevasse areas where no accurate displacements can be detected. As a first filter, after verifying average zero displacement for stable areas outside the glacier, all the computed velocity vectors outside the glacierised areas are removed by using the digitised glacier outlines (Heid and Kääb, 2012). The latter are manually digitised based on drone and satellite images and correspond to the end of the summer of every balance year under consideration. Then, a median filter is applied which removes velocity components that deviate too much from the surrounding vectors (Heid and Kääb, 2012; Nagy et al., 2019). Finally, we also impose a maximum velocity threshold derived from the modelled velocities in Zekollari et al. (2013), which are constrained with field observations. In other words, we limit the maximum surface velocity at every grid cell to the veloc- ity modelled in Zekollari et al. (2013) $+20 \%$. The latter is a margin to take into account potential errors present in the study of Zekollari et al. (2013). However, after analysis this proved to not be necessary as these high values did not occur. The raw velocity maps containing gaps after filtering are then interpolated using a cubic spline interpolation (Ruiz et al., 2015). As validation, we compare the obtained velocities with measured velocities from stakes.

\subsection{Ice flux divergence from ice thickness and surface velocities}

The ice flux divergence (in mi.e. $\mathrm{yr}^{-1}$ ) corresponds to the local upward or downward flow of ice relative to the glacier surface. It represents the difference between the ice supplied from upstream and lost downstream at a particular position. It is defined to be negative for upward motion (mass supplied to the surface, also referred to as the emergence velocity) 


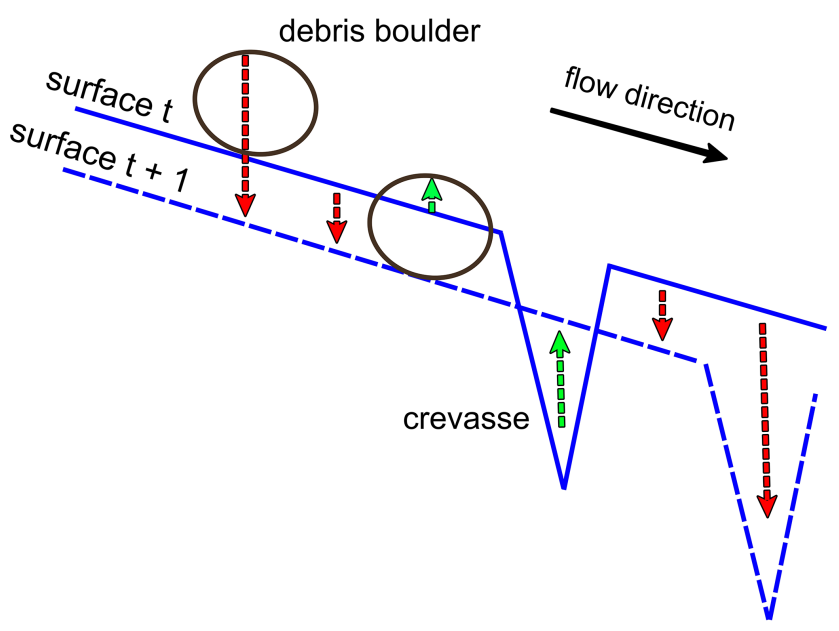

Figure 4. The advection of surface topography (such as debris boulders and crevasses) can alter surface elevation changes between time step $t$ and $t+1$ (red: negative $\partial h / \partial t$; green: positive $\partial h / \partial t$ ). The net effect on the surface elevation depends on the amount of lowering and the vertical extent of the moving features on the glacier surface.

and positive for downward motion (mass is removed from the surface, also referred to as the submergence velocity).

Different approaches exist to calculate the ice flux divergence, ranging from the use of 3D ice flow models (Seroussi et al., 2011; Vincent et al., 2021) to the use of simple geometric calculations and flux gates (Nuimura et al., 2011; Berthier and Vincent, 2012). The important distinction is the simplicity and the resolution with which they can be calculated. In this study, the ice flux divergence is computed for each grid cell by combining surface velocities and ice thickness according to Eq. (3):

$\nabla \cdot \boldsymbol{q}=F\left(u_{\mathrm{s}, x} \frac{\partial H}{\partial x}+u_{\mathrm{s}, y} \frac{\partial H}{\partial y}+H \frac{\partial u_{\mathrm{s}, x}}{\partial x}+H \frac{\partial u_{\mathrm{s}, y}}{\partial y}\right)$.

The right side of Eq. (3) contains two horizontal ice flux components, of which the first corresponds to the ice thickness divergence and the second one to the velocity divergence (Reeh et al., 2003). Both are computed from the relevant derivatives. $F$ is the depth-averaged glacier velocity ratio $\left(\bar{u} / u_{\mathrm{s}}\right)$. For an isothermal glacier with negligible basal sliding and Glen's flow coefficient $n=3, F$ is 0.8 . However, the Morteratsch-Pers glacier complex is assumed to be a temperate alpine glacier complex which is accompanied by basal sliding. According to Zekollari et al. (2013), internal deformation accounts glacier-wide on average for $70 \%$ of the flow and basal sliding for the remaining $30 \%$. However, in the ablation area the contribution of internal deformation is most likely even higher. Therefore, for the standard runs in this study, we take an $F$ value of 0.9 . However, the $F$ value may vary locally (Zekollari et al., 2013), and varying this parameter will therefore be part of the sensitivity analysis.

\subsection{Spatial scales of the ice flux divergence}

In contrast to the surface elevation changes, for which the accuracy is expected to be high, the computed ice flux divergence is subject to larger uncertainties. This uncertainty directly relates to the large uncertainties in the reconstructed ice thickness field. Moreover, a considerable part of the uncertainty also originates from the spatial scales that need to be considered: due to longitudinal stresses, the local ice dynamics depend not only on the local glacier geometry (an assumption of the shallow ice approximation; see e.g. Hutter and Morland, 1984) but also on the surrounding geometry, typically over scales corresponding to several times the local ice thickness (accounted for in higher-order and full Stokes models; see e.g. Zekollari et al., 2014, where such a model was applied for this glacier complex). Local gradients of the ice thickness and the velocity are often magnified when they are determined on a numerical grid with a central difference scheme. This is directly reflected in the ice flux divergence pattern. Therefore, to make the ice flux divergence solution independent of the resolution and to take non-local stresses into account, larger scales must be considered (Reeh et al., 2003; Rounce et al., 2018). To date, studies applying the continuity equation method usually resampled the ice flux divergence grid to a much lower resolution (Nuimura et al., 2011; Seroussi et al., 2011; Rounce et al., 2018) or considered a flux gate approach (Berthier and Vincent., 2012; Vincent et al., 2016; Brun et al., 2018). However, as we aim for a high resolution of the SMB determination in this study and to obtain spatial variations in the ice flux divergence field, we opt to retain the $25 \mathrm{~m}$ resolution and to apply a filter to consider larger scales for the calculation of the ice flux divergence.

Different filters have been applied, of which most are constant box filters (e.g. mean, median) with a strong variation in size (up to 10000 m) (Kääb and Funk, 1999; Seroussi et al., 2011; Rounce et al., 2018). Such filters give equal weight to cells within the box irrespective of their distance from the point in consideration (Kamb and Echelmeyer, 1986; Le Brocq et al., 2006). In this way, the effects of local phenomena (such as an ice fall or an acceleration in the glacier flow) are spread out uniformly when these filters are applied over larger distances, which implies that there are no localised peaks in the flux divergence field. Also, these filters have an abrupt cut-off point where the weighting becomes zero (Le Brocq et al., 2006). Furthermore, effects of perturbations in, for example, ice thickness have been demonstrated to fade out exponentially for ice flow (Kamb and Echelmeyer, 1986). Because of all these reasons, we apply in this study a local exponential decay filter (Eq. 4):

$$
\nabla \cdot \boldsymbol{q}_{[x, y]}=\sum_{i=- \text { dist }}^{\text {dist }} \sum_{j=- \text { dist }}^{\text {dist }} W_{[x+i, y+j]} \nabla \cdot \boldsymbol{q}_{[x+i, y+j]} .
$$

In Eq. (4), dist is the maximum distance of a cell which is taken into account in the exponential decay filter (set at 
$2.5 \mathrm{~km}), i$ and $j$ are indices, and $W$ represents the weight of a particular cell at position $[x+i, y+j]$ (Le Brocq et al., 2006):

$W_{[x, y]}=e^{-\frac{1}{\mathrm{sl}} \cdot \sqrt{\left(x^{\prime}-x\right)^{2}+\left(y^{\prime}-y\right)^{2}}}$.

In Eq. (5), $x$ and $y$ are the coordinates of the point being filtered, while $x^{\prime}$ and $y^{\prime}$ are the coordinates of the weighted points, and sl is the scaling length and is a crucial parameter determining how fast the exponential filter fades. This parameter directly relates to the length scale over which the longitudinal stresses determine the local ice flow. Theoretically, this scaling length is in the range of 1-3 times the local ice thickness for valley glaciers and 4-10 times for ice sheets (Kamb and Echelmeyer, 1986; Le Brocq et al., 2006). For our experiments, we vary the scaling length depending on $A$ times the local ice thickness (Eq. 6). In this way, we incorporate variations within the study area into the exponential decay filter, and we account for non-local flow coupling. The latter was shown to be an improvement compared to fixedsize filters (Le Brocq et al., 2006). As such, the ice flux divergence in areas with a larger ice thickness is considered over a larger distance compared to areas with a smaller ice thickness.

$\operatorname{sl}[x, y]=A \cdot H[x, y]$

with

$A \in\{0: 1: 10\}$

To provide for conservation of mass within our survey area, the filtered result in each grid cell is multiplied by the ratio of the net flux divergence (sum of all ice flux divergences) before and after filtering. To determine the optimal procedure to include the effects of (longitudinal) stresses and uncertainty in the input data, we perform multiple experiments with the exponential decay filter. For this, we examine whether (i) the ice flux divergence, (ii) the gradients of velocity and ice thickness, or (iii) both should be considered over larger spatial scales for optimal results in the determination of the SMB.

First, the ice flux divergence is considered over larger spatial scales by applying the exponential decay filter to the ice flux divergence field. Second, to compensate solely for the effects of large gradients, the gradients are considered over larger spatial scales. We therefore apply the exponential filter to the ice thickness and velocity gradients and calculate the ice flux divergence using these smoothed gradients. Third, to compensate for the negative effects of very large scaling lengths for both previous experiments and the biases related to both, we filter twice. Hence, both filters are applied after each other. In this way, the smoothness of the ice flux divergence field increases, while the top values are not damped as much as when applying a filter once with a long scaling length. This tends to reduce the distance over which the filtering must be performed, which is favourable to preserve local variations.

For every experiment, the modelled and measured SMB values at the position of the stakes are compared (see Sect. 2.2). As metrics to quantify the performance of the procedure, the mean absolute error (MAE) and the root mean square error (RMSE) are used (Eqs. 7 and 8). The MAE is defined as the absolute difference between the modelled and the measured SMB. The RMSE on the other hand takes into account the variance of the errors; $n$ is the number of stake measurements. The uncertainty in the SMB measurements is estimated to be $\pm 0.2 \mathrm{~m}$ i.e. $\mathrm{yr}^{-1}$ and is also considered in the analysis. More specifically, for each filter option we carry out 100 versions in which we perturb the measured SMB. This is done by randomly adding a value between -0.2 and 0.2 distributed around 0 . Then, for the option under consideration, the average MAE and RMSE are calculated from Eqs. (7) and (8), where $n$ is the number of SMB measurements for every year (see Sect. 2.2), $i$ is an index ranging from 1 to $n$ (16), and $x_{i}$ and $y_{i}$ are the Cartesian coordinates of the different stakes under consideration.

$\begin{aligned} \text { MAE } & =\frac{1}{n}\left(\left|\sum_{i=1}^{n} b_{\mathrm{s}, \text { modelled }}\left(x_{i}, y_{i}\right)-b_{\mathrm{s}, \text { measured }}(i)\right|\right) \\ \text { RMSE } & =\sqrt{\frac{\sum_{i=1}^{n}\left(b_{\mathrm{s}, \text { modelled }}\left(x_{i}, y_{i}\right)-b_{\mathrm{s}, \text { measured }}(i)\right)^{2}}{n}}\end{aligned}$

\section{Results}

\subsection{Surface elevation changes and filtering}

The accuracy of the elevation product is first assessed by comparing the photogrammetrically created DSMs with GVPs, randomly divided over the study area. MAE between measured and modelled elevation is on the order of a few centimetres (Table 2), which is similar to values found in other studies (Whitehead et al., 2013; Immerzeel et al., 2014; Wigmore and Mark, 2017; Zhang et al., 2019). As such, the accuracy of the created DSMs is high. Furthermore, the mean error (ME) is close to zero, which indicates that the created DSMs are not biased. For 2017, the slightly larger MAE is probably caused by a smaller number of GCPs combined with a reduced visual content because of fresh snow on the glacier surface. Further, the small MAE and RMSE of the DSM in 2020 highlight the advantage of using an RTK equipped with an RTK GPS (P4RTK) for which a smaller number of GCPs are needed to reach similar or better accuracies compared to a classic set-up (UAV without RTK correction).

Then, the accuracy of the surface elevation changes is assessed by comparing the elevation differences in rectangular areas outside the glacierised areas for two regions (see 
Table 2. Mean absolute error (MAE), mean error (ME) and root mean square error (RMSE) of the elevation differences between the DSMs and the GVPs in different years. Units are in mi.e. The GCP density is the number of GCPs per square kilometre, while the column of GVPs represents the total number of GVPs in each year.

\begin{tabular}{rrrrrrr}
\hline Year & MAE & ME & RMSE & GCP density $\left(\mathrm{km}^{-2}\right)$ & GVPs & UAV used \\
\hline 2017 & 0.09 & -0.07 & 0.16 & 11 & 10 & P4PRO \\
2018 & 0.06 & -0.02 & 0.22 & 24 & 34 & P4PRO \\
2019 & 0.08 & 0.03 & 0.16 & 18 & 27 & P4PRO \\
2020 & 0.07 & 0.03 & 0.10 & 11 & 19 & P4RTK \\
\hline
\end{tabular}

Fig. 6), where the topography is assumed to be mostly stable (Yang et al., 2020). The histograms for the 3 different balance years show that most of the differences range between -0.2 and $0.2 \mathrm{~m}$, which indicates that there is no large absolute offset between the DSMs of the different years (Fig. 5). For region 2, we find a larger standard deviation (SD) for the 2017-2018 difference, which appears to be caused by a small horizontal shift, which produces larger elevation differences (both negative and positive) in this steeper area. For the more gently sloping glacier surface, the effects are negligible. The larger SD for the 2019-2020 difference in region 1 is caused by an area where a part of the bare surface was eroded by a melt river, producing a tail of negative elevation differences. In general, the above analysis reveals that the vertical uncertainties resulting from the DSM differencing are limited.

The different maps for the 3 balance years display a very detailed pattern of surface elevation changes (Fig. 6). For example, alternating positive and negative surface elevation changes are noticeable and can be explained by the advection of local glacier surface topography due to glacier movement (see also Fig. 4). In addition, significantly less negative $\partial h / \partial t$ values at the left side of Vadret da Morteratsch, especially where the glacier protrudes towards the north, are likely the result of a debris cover insulating the ice below and decreasing the melting rate (Reznichenko et al., 2010; Rounce et al., 2018; Rossini et al., 2018). The latter was also observed by the study of Rossini et al. (2018) focussing on the elevation differences on the front of Vadret da Morteratsch in the summer of 2016. Only at the terminal ice cliff can significantly higher $\partial h / \partial t$ values be observed (Immerzeel et al., 2014). Given that the ice fluxes can be assumed to remain relatively constant over the 3 years in consideration, the elevation changes indicate that 2017-2018 was the year with the most negative SMB (which is confirmed by field measurements) (see Fig. 11). Further, large positive surface elevation changes can be distinguished for 2019-2020 at the highest part of Vadret Pers. This is probably the result of avalanches originating from the steep accumulation area and persistent snow cover in these areas. This is striking as surface elevation changes farther down on the glacier are generally more negative compared to 2018-2019; i.e. the SMB gradient on Vadret Pers is steeper in 2019-2020 compared to 2018-2019.
Alternating positive and negative surface elevation changes are occurring, caused by the advection of surface topography (Figs. 4 and 6). We correct for these non-SMB features by flow-correcting the DSMs (see Sect. 3.2). The alternating pattern has clearly faded (Fig. 6d). At the top of the ablation area of Vadret da Morteratsch, near the ice fall, the $\partial h / \partial t$ values at the margin of the area are unrealistic because of inaccurate velocity calculations (see Fig. 7) and margin effects of the longitudinal slope. However, this area lies outside the area under investigation (see Fig. 7).

\subsection{Glacier surface velocity}

The velocity map derived from feature tracking and filtered for errors (see Sect. 3.3) contains several voids (Fig. 7a). This is caused by a lack of correlation between the 2 years, which is typically related to deformations of the surface, repositioning of supraglacial melt streams, and the presence of snow cover or debris. The latter hampers an accurate tracking between 2 consecutive years. To fill these gaps, cubic spline interpolation is used (Fig. 7b).

Comparison with the velocities obtained by field measurements using ablation stakes (based on a high-precision RTK GPS system, estimated accuracy of approx. $0.1 \mathrm{~m} \mathrm{yr}^{-1}$ ) reveals a good agreement. We find the ME and RMSE to be $0.01 / 1.7 \mathrm{~m} \mathrm{yr}^{-1}$ for $2017-2018,0.99 / 1.9 \mathrm{~m} \mathrm{yr}^{-1}$ for $2018-$ 2019 and $-0.37 / 1.8 \mathrm{~m} \mathrm{yr}^{-1}$ for 2019-2020 (Fig. 8).

The surface velocities of 2017-2018 are higher compared to 2018-2019. Because the surface velocities in 2019-2020 also appear to be slightly larger compared to 2018-2019, it might be due to a larger amount of basal sliding in these 2 balance years. The latter can be caused by an increased supply of meltwater lubricating the glacier's base, which can be linked to a more negative $\partial h / \partial t$ in 2017-2018 and 20192020 compared to 2018-2019 (see also Fig. 6).

\subsection{Ice flux divergence}

After considering various spatial scales and filter procedures to determine the ice flux divergence, we find optimal results (lowest MAE, RMSE and minimal scaling length; see Sect. 5.2) when both filters are applied after each other for a scaling length of $4 \times H$ to smooth the ice thickness and velocity gradients and a scaling length of $1 \times H$ to smooth the 

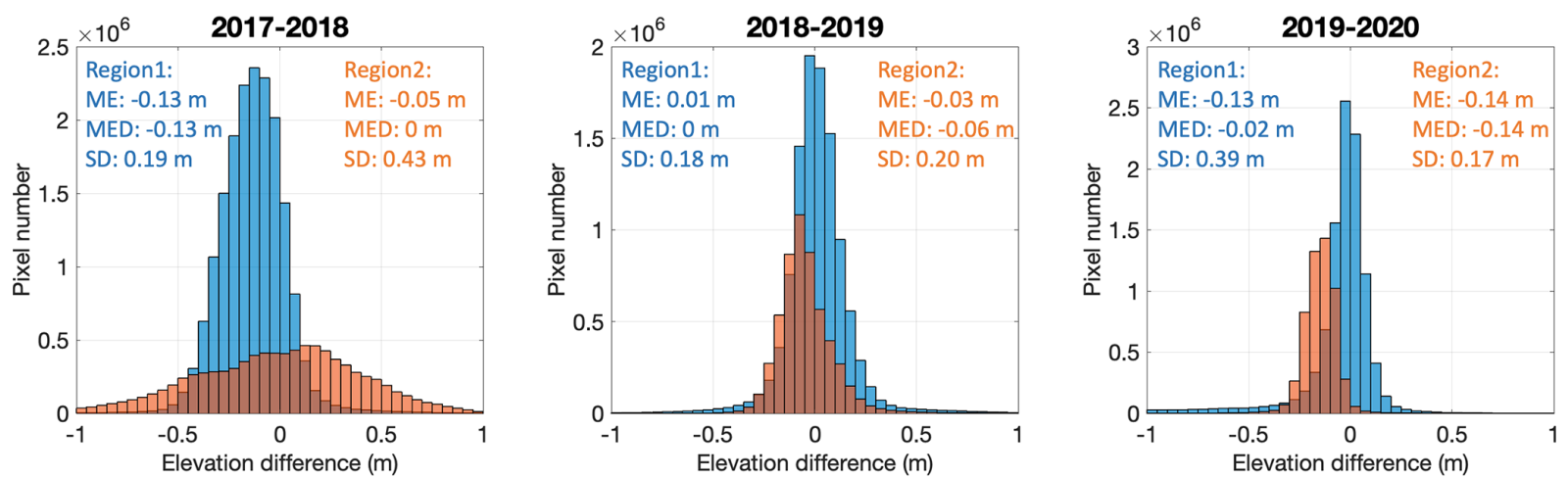

Figure 5. Histograms of elevation differences for the different balance years considered. The mean error (ME), median error (MED) and standard deviation (SD) are added for each region. Regions 1 and 2 are defined in Fig. 6 a.

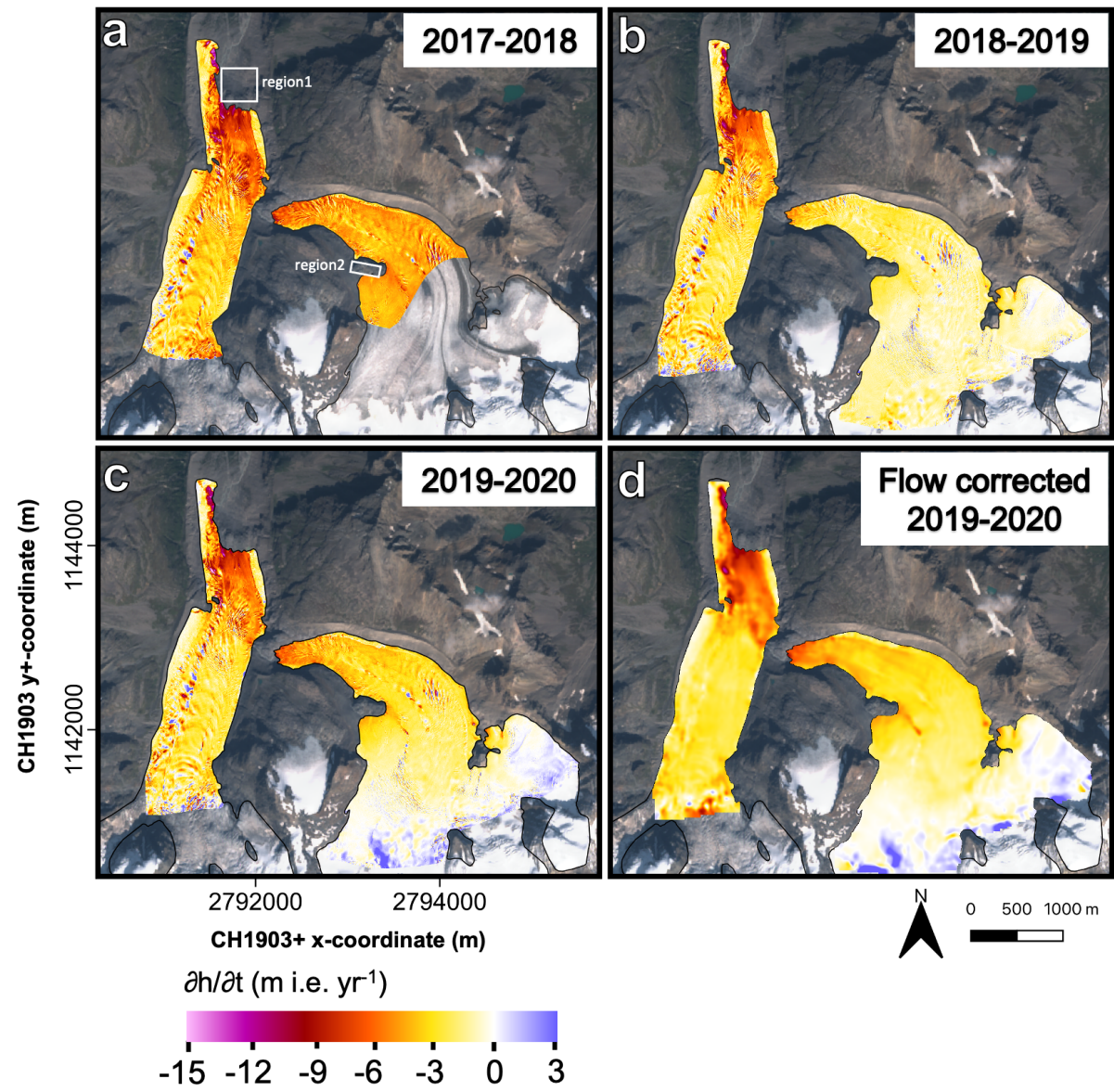

Figure 6. Surface elevation changes for (a) 2017-2018, (b) 2018-2019 and (c) 2019-2020. The spatial resolution is equal to $8 \mathrm{~cm}$. Panel (d) shows the surface elevation changes for 2019-2020 after flow correction. The outline of the glacier corresponds to the latest year of observation for every balance year in consideration. The two white boxes (region 1 and region 2) are stable areas which are used for the error analysis. The background image is a Sentinel-2 true colour composite satellite image from 13 September 2020.

ensuing ice flux divergence (see Sect. 3.5). These values are close to the theoretical values of the fundamental longitudinal scaling length for valley glaciers, mentioned in Kamb and Echelmeyer (1986). It shows that the data need to be considered over large spatial scales, which implies that the ice flux divergence field must be sufficiently smooth to give accurate results.

The computed ice flux divergence is clearly characterised by negative values over both glacier tongues (Fig. 9). This represents horizontal compression and associated vertical 

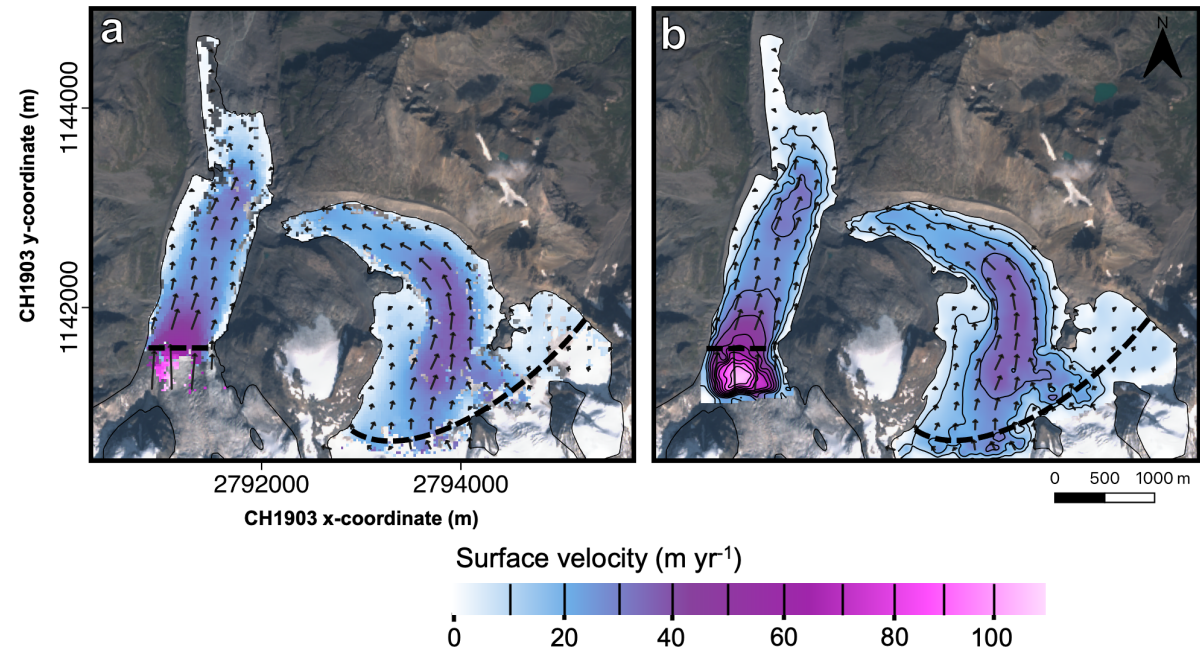

Figure 7. Horizontal surface velocities derived from feature tracking between 2019 and 2020. (a) Filtered surface velocity, (b) void-filled filtered surface velocity. The black arrows indicate the flow direction. The dashed black line indicates the limit of the glacier area where the velocity is modelled without many gaps (area used for further analyses, e.g. when calculating ice flux divergences). The background image is a Sentinel-2 true colour composite satellite image from 13 September 2020 . The contour lines are added for every $10 \mathrm{~m} \mathrm{yr}^{-1}$, and they are indicated in the colour bar.

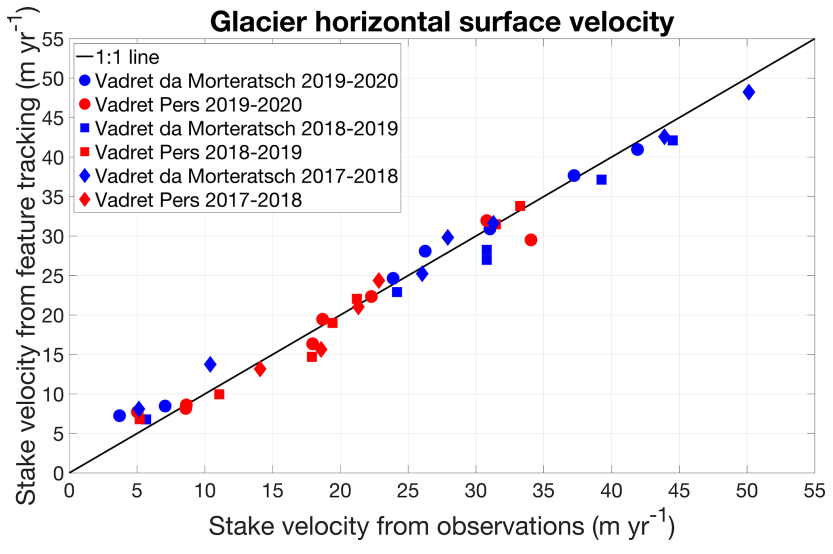

Figure 8. Comparison between surface velocities at stakes from field observations (high-precision GPS measurement at stakes) and from feature tracking.

extension, which is generally expected for ablation areas (e.g. Kääb and Funk, 1999). This horizontal compression translates into an ice supply towards the surface (emergence velocity), which counters the effect of the negative mass balance on the local ice thickness change (and neutralises it in case the glacier is in equilibrium with the local climatic conditions). The ice flux divergence reaches a minimum between 500 and $1000 \mathrm{~m}$ from the terminus of the Vadret da Morteratsch, with values close to $-4 \mathrm{mi}$ i.e. $\mathrm{yr}^{-1}$ (Fig. 9). In this area, both the ice thickness (Fig. 3) and the surface velocity (Fig. 7) decrease significantly, which leads to large negative gradients and hence upward motion (negative ice flux divergence). It is therefore not surprising that there is a complex pattern of transverse crevasses in this area (see Fig. 2). The maximum ice flux divergence at the eastern side of Vadret da Morteratsch near the former confluence area with Vadret Pers is suspicious. This is likely caused by the very large ice thickness gradient because of the contribution of the underestimated ice thickness in the THIZ dataset. In this area, the THIZ dataset revealed zero ice thickness because of an overestimation of the bedrock elevation (Fig. 3).

\subsection{SMB from UAV}

The final step of the method is to add the surface elevation changes (see Fig. 6) and the computed ice flux divergence (Fig. 9) to obtain the SMB (see Eq. 1). The final product, the modelled SMB for the 3 balance years, is shown in Fig. 10. The 3 years in consideration clearly show a rather similar pattern. Areas with a less negative SMB are located at the same locations (e.g. western margin of Vadret da Morteratsch). Areas with the most negative SMB are also at the same location (e.g. glacier fronts). The ice flux divergence is prominently not able to compensate for the very negative SMB so that there is net mass loss everywhere, and the elevation changes are less than zero. The most negative SMB (up to $-13 \mathrm{~m}$ i.e. $\mathrm{yr}^{-1}$ ) is found at the front of Vadret da Morteratsch in 2017-2018, which is in accordance with the SMB measurements. This concerns the lowest area, which is also quasi-stagnant with a very limited supply of ice from upstream (see Fig. 9). The presence of certain irregular patches with a smaller or larger SMB is caused by artefacts in the flow correction method (see Sect. 3.2 and Fig. 6d). This is because the flow correction method cannot trace all displacements exactly (rocks fall over, crevasses deform, supraglacial 


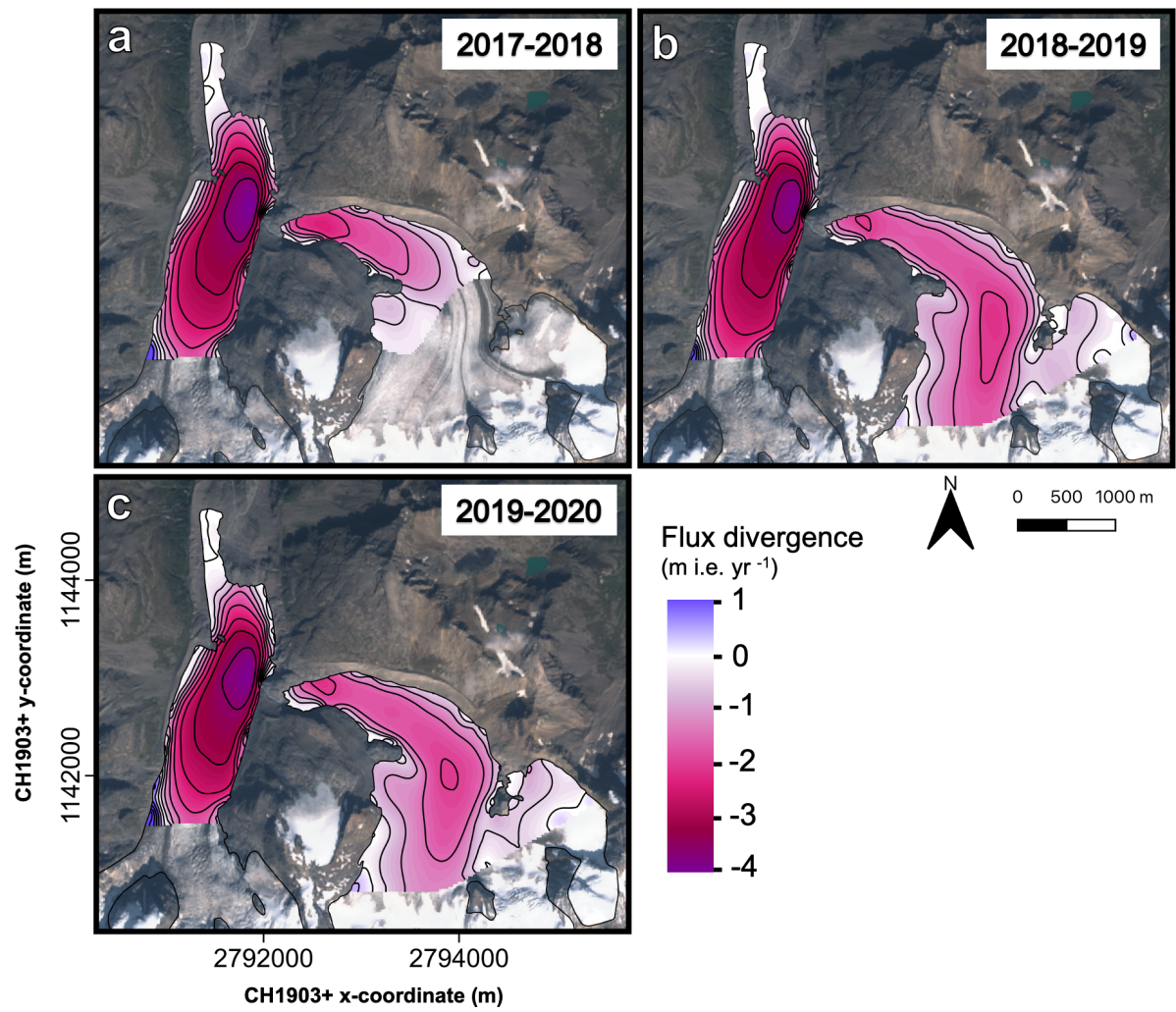

Figure 9. Maps of the modelled ice flux divergence for the different years under consideration. Contours are added for every $0.5 \mathrm{mi}$.e. $\mathrm{yr}^{-1}$. The background image is a Sentinel-2 true colour composite satellite image from 13 September 2020.

melt streams are positioned on different locations, etc.) because the velocity field is not fully accurate and because the calculation of the longitudinal slope also affects the result.

The associated point-by-point comparison between modelled and measured SMB confirms the good match, with deviations generally smaller than $0.5 \mathrm{~m}$ i.e. $\mathrm{yr}^{-1}$ (Fig. 11). Next to that, the ME is close to zero, indicating that the derived optimal SMB fields are not biased (Fig. 11). Only for Morteratsch in 2018-2019 is the ME slightly larger. The largest differences are found at the front of Vadret Pers (Fig. 11). Near the glacier front, the ice flux divergence is likely underestimated as a result of overestimated ice thickness in this area of the THIZ dataset. The latter decreases the ice thickness gradient in this area substantially.

In 2019, stake M26 (see Fig. 2) was replaced by M27 (and installed at a higher location) because it was located in the middle of a field of transverse crevasses during the survey in 2019. It is noticeable that this location was characterised by a more negative SMB compared to the surrounding areas in both 2017-2018 and 2018-2019 (see Figs. 10 and 11), which is probably caused by a more exposed position on an ice serac.

For the optimal SMB fields, a minimum MAE of $0.21 \mathrm{mi}$ i.e. $\mathrm{yr}^{-1}$ is obtained for Vadret da Morteratsch in 2019-2020 (Fig. 11). The MAE and RMSE are somewhat larger for Vadret Pers, with a maximum of $0.61 \mathrm{mi}$ i.e. $\mathrm{yr}^{-1}$ in 2018-2019, which is mainly caused by the larger deviation for the lowest two stakes (Fig. 11).

\subsection{Lateral variations in the SMB pattern}

Using the continuity method based on close-range (UAV) remote sensing data clearly reveals a much more detailed picture of SMB than is possible from a stake network at a limited number of locations. This is evident in the lateral heterogeneity of SMB, which is often overlooked when considering elevation as the prime variable to plan the stake locations. In Fig. 12 the difference is shown between the UAVderived SMB field and an SMB field only determined by elevation as derived from a linear fit of the stake measurements with altitude (see the inset of Fig. 12). In general, the largest differences occur close to the margin of the glaciers and around their front. The differences at the glacier margin of Vadret da Morteratsch are mainly related to a thick debris cover, which when sufficient in thickness has an insulating effect that reduces the glacier melt (e.g. Rounce et al., 2018; Verhaegen et al., 2020). For example, for the heavily debris-covered area where Vadret da Morteratsch protrudes towards the north, the SMB is $-1.5 \mathrm{~m}$ i.e. $\mathrm{yr}^{-1}$ below the debris and up to $-12 \mathrm{mi}$ i.e. $\mathrm{yr}^{-1}$ for the ice next to the debris. A thin layer of debris and the terminal ice cliff (Immerzeel 


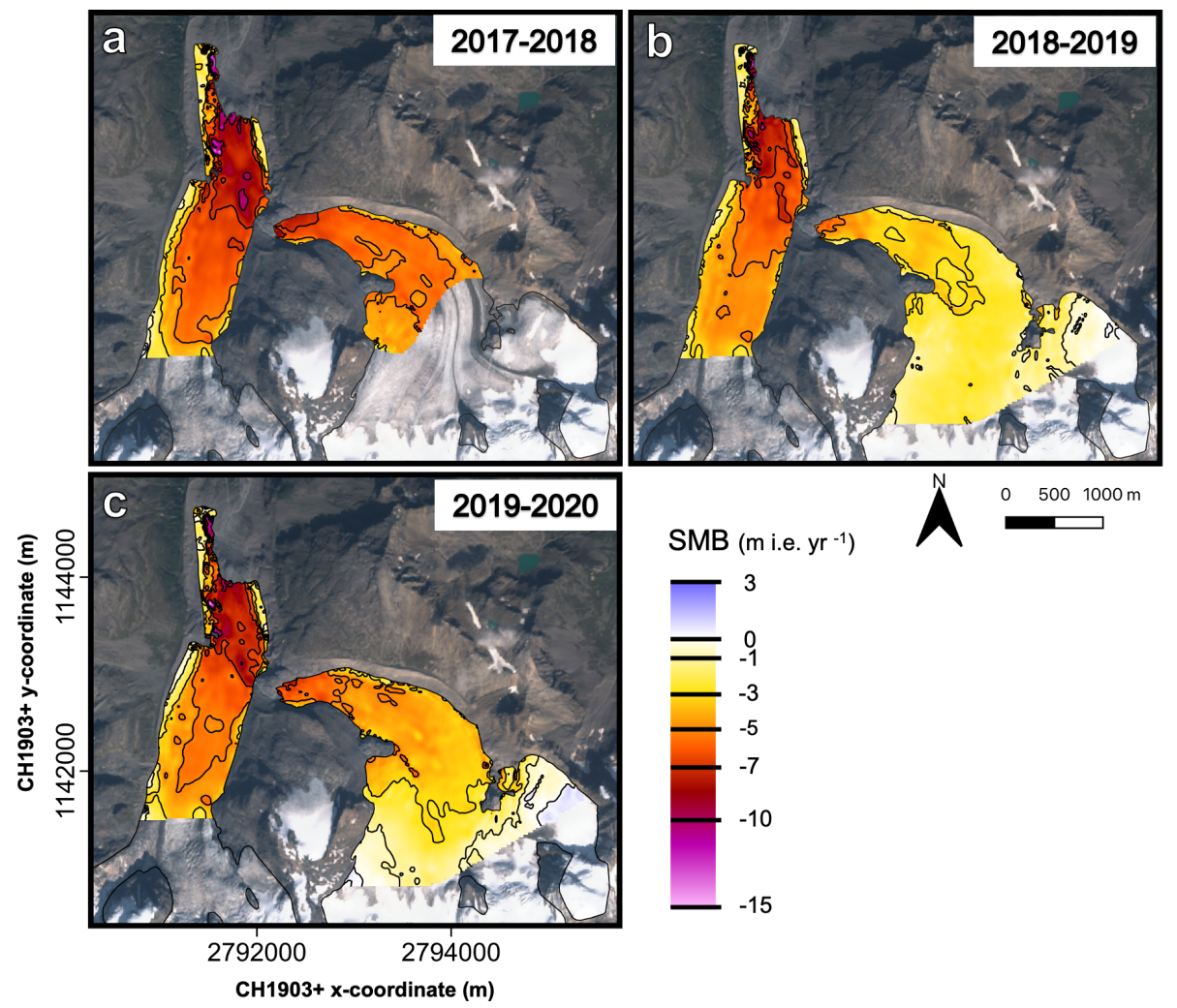

Figure 10. Maps of the modelled SMB fields. Contours are added for specific values (indicated on the colour bar). The background image is a Sentinel-2 true colour composite satellite image from 13 September 2020.

et al., 2014) further reinforce the melt here, explaining this very high ablation rate (Rossini et al., 2018). The melt ratio is therefore equal to 0.125 , which means that there is $87.5 \%$ less melt under the debris at this location. This corresponds to a debris thickness of more than $50 \mathrm{~cm}$ when a typical average value of the characteristic debris thickness is used (Anderson and Anderson, 2016; Rounce et al., 2018). Such thicknesses are very likely in this area. During the fieldwork campaigns, boulder supply from the moraines was observed on several occasions, which was also documented in the Himalaya by Van Woerkom et al. (2019).

Another major feature is the presence of patches with a clearly more negative SMB when relying on the UAV-derived SMB field. These differences relate to stationary areas at local ice fronts or collapsing ice caves. While the first are real SMB variations (caused by more irradiation and/or less snow), the latter ones are not caused by the SMB. These collapsing ice caves clearly appear to occur near stagnant ice and at the bottom of the glacier, where meltwater forms a cave below the ice (Fig. 12). These caves collapse when the overlying ice becomes too thin due to melting at the surface. For the other areas, the difference between the SMB fields is generally smaller, between -0.5 and $0.5 \mathrm{mi}$ i.e. $\mathrm{yr}^{-1}$. This is on the same order as the MAE and the RMSE and is slightly larger than the expected accuracy of the SMB measurements. The mean of the differences corresponds to $0.56 \mathrm{~m}$ i.e. $\mathrm{yr}^{-1}$, which is specifically caused by the western side of the Morteratsch glacier, with a thick layer of debris (see Figs. 2 and 12). Using the simple linear fit to derive the SMB pattern would overestimate the ablation in the surveyed area by $2.4 \times 10^{6} \mathrm{~m}^{3}$.

\section{Uncertainty analysis of the selected data, parameters and filters}

The surface elevation changes and the ice flux divergence contribute separately to the surface mass balance, implying that errors and uncertainties in both terms do not influence each other but directly affect the determined SMB (Eq. 4). It is therefore crucial to determine the extent to which the uncertainty in both affects the results of the applied method. In addition, we evaluate the results of the different filter procedures of the ice flux divergence.

\subsection{Dependence on the data and $F$ value used}

To study the dependence of the applied method on the uncertainty attributable to the used data and $F$ value, we create 100 perturbed fields of the surface elevation changes, the surface velocity, the $F$ value and the ice thickness. After that, we 

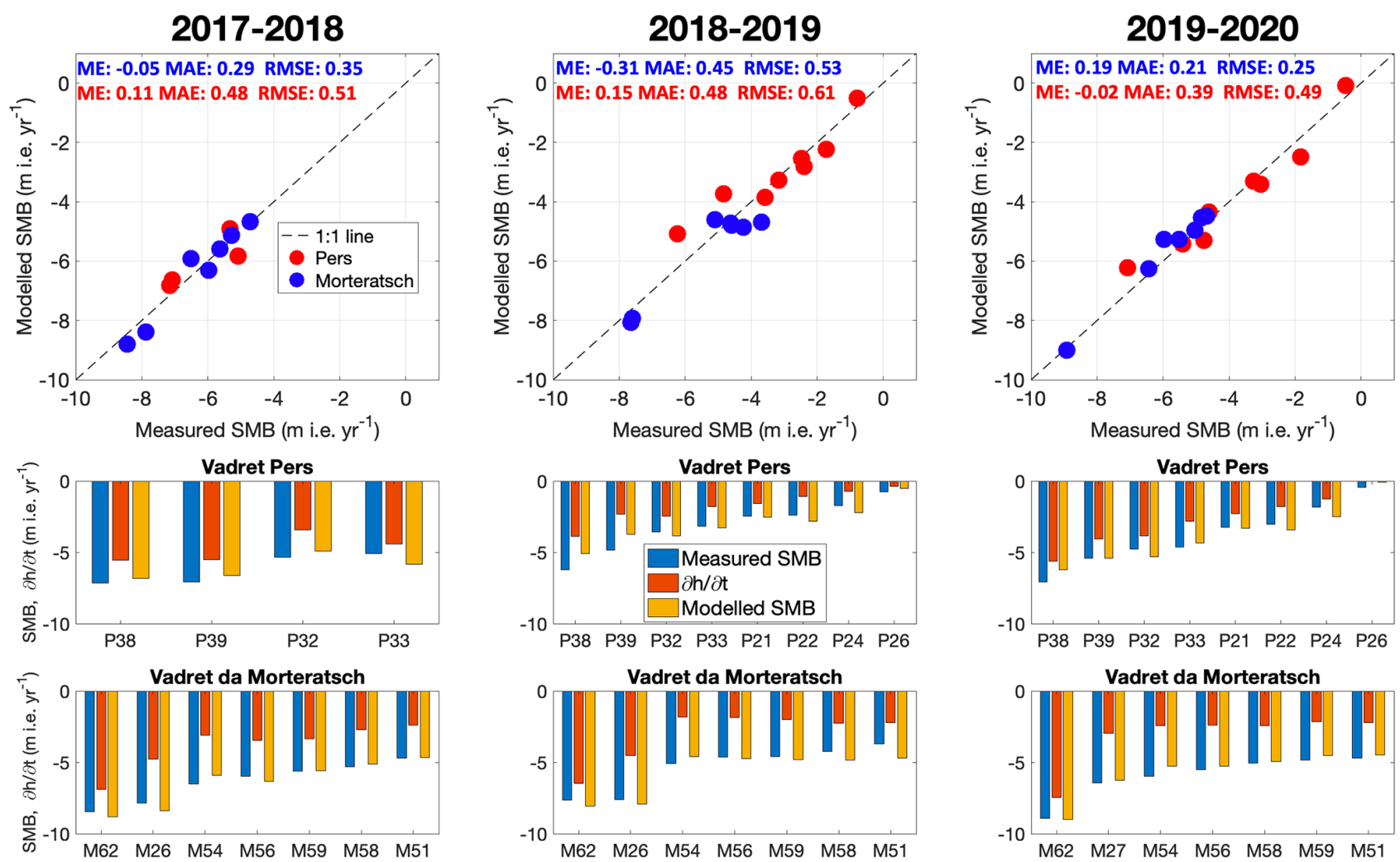

Figure 11. Point-by-point comparison of modelled and measured SMB. In the lower panels, the difference between the modelled SMB (yellow bar) and the local elevation change (red bar) results from the modelled ice flux divergence. The labels refer to the stake names as

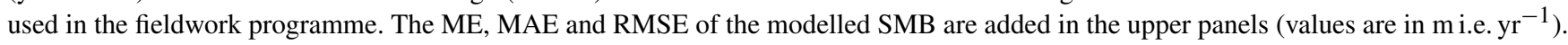

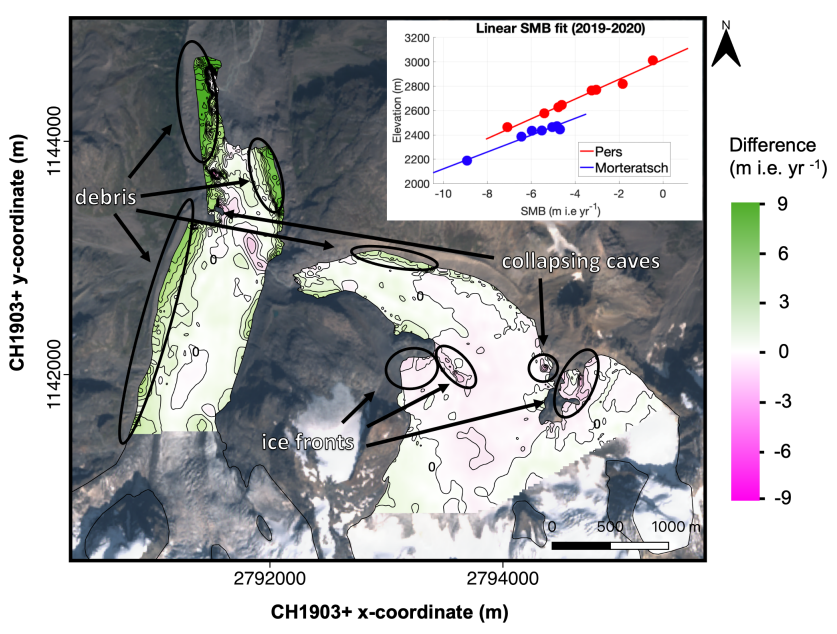

Figure 12. The inset shows a linear SMB fit based on stake measurements. The main figure shows the difference between the UAVderived SMB and the linearly derived SMB. The background image is a Sentinel-2 true colour composite satellite image from 13 September 2020. Contour lines are added for every metre. Labels are added for the contour of value $0 \mathrm{~m}$ i.e. $\mathrm{yr}^{-1}$. do the calculations, using the perturbed data for one dataset and the original data for the other ones. Next, the MAE of modelled versus measured SMB is calculated 100 times and for all years, and the standard deviation of this MAE is determined. For the analysis, the different input fields are perturbed using random patches with a diameter (uniformly distributed) between $50 \mathrm{~m}$ (local errors at grid level) and $500 \mathrm{~m}$, with perturbation values normally distributed with a standard deviation of half the error estimate.

The uncertainty in the surface elevation changes is assumed to be correlated in space, i.e. depending on a pattern across the glacier (e.g. Fischer et al., 2015). Therefore, the $\partial h / \partial t$ fields are perturbed with perturbations of maximum $0.5 \mathrm{~m}$ (plausible maximum value for the multiannual $\partial h / \partial t$ from UAV data) (see Table 2). Regarding surface velocity, we use error estimates of $10 \%$ of the observed velocity, similar to the expected accuracy (see Sect. 4.2). Besides velocity itself, the assumption of a constant $F$ value is rather unrealistic (Zekollari et al., 2013). Ice flow over basal irregularities causes variations in $F$. Previous research showed for example $F$ to be larger over basal highs and smaller over basal lows, and glacier areas with more basal sliding could also be characterised by a larger $F$ value (Reeh et al., 2003). Therefore, we apply perturbations using an $F$ value between 
0.85 and 0.95 . Concerning ice thickness, we apply perturbations with an error estimate of $30 \%$, taken from Zekollari et al. (2013).

The effect of perturbation of $\partial h / \partial t$ on the determined SMB is small, with a standard deviation of less than $0.1 \mathrm{~m}$ i.e. $\mathrm{yr}^{-1}$ for both glaciers (Fig. 13). As a result, the results of the applied method are not very dependent on (small) perturbations in $\partial h / \partial t$. Changes in the $F$ value and surface velocity also appear to have minor sensitivity, especially concerning Vadret Pers. Regarding Vadret da Morteratsch, the applied perturbations of the surface velocity have an SD of the derived SMB of $0.3 \mathrm{~m}$ i.e. $\mathrm{yr}^{-1}$, which is not negligible (Fig. 13). The ice thickness distribution, however, is for both glaciers undoubtedly most crucial for the determination of the SMB and even more so for Vadret da Morteratsch.

We therefore conducted some additional tests with both (THIZ and THIL) individual ice thickness datasets and for different combinations. For Pers glacier, the Langhammer dataset proved to be slightly better (MAE of 0.49 versus $0.60 \mathrm{~m}$ i.e. $\mathrm{yr}^{-1}$ ), while for Morteratsch, the Zekollari dataset

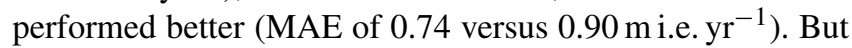
in general, all combinations tested gave poorer results, which encouraged us to use the average ice thickness in this study. Further, it should be mentioned that the above analysis is valid for the glacier-wide mean SMB deviations. For local point measurements, the uncertainty related to the used data or the $F$ parameter might be larger.

\subsection{Evaluation of procedures to filter the ice flux divergence}

As the ice flow at a given location is determined by the surrounding glacier geometry (i.e. not only by its local geometry) and to avoid non-physical oscillations in the flux divergence field (as a result of fine grid spacing), it appears to be necessary to consider various spatial scales over which the ice flux divergence needed to be determined and different filtering procedures (see Sect. 3.5). The results of each possible combination are shown in Fig. 14.

By only applying the exponential decay filter to the ice flux divergence field (moving down in the matrix), we find minimum MAE and RMSE values when the scaling length is equal to 5 times $H$ (MAE for Morteratsch-Pers is $0.51 \mathrm{mi}$.e. $\mathrm{yr}^{-1}$ ). Such a large scaling length indicates that the ice flux divergence field must be smoothed significantly and therefore becomes entirely smeared with limited variation in the ablation area. One of the reasons for this high value are large ice thickness and velocity gradients resulting from solving ice flow processes on a high-resolution numerical grid. To compensate for the effects of large gradients, the second option is to consider the gradients over larger spatial scales. We do this by applying the exponential filter to the ice thickness and velocity gradients and calculating the ice flux divergence using these smoothed gradients (moving to the right in the matrix). A minimum MAE of 0.54 m i.e. $\mathrm{yr}^{-1}$ is reached as soon as the velocity and ice thickness gradients are considered over 6 times $H$. The solution to compensate for the negative effects of a very large scaling length for both previous filters and the biases related to both is to filter twice, as is elucidated in Sect. 3.4 and shown in Sect. 4.3. As soon as the ice thickness and velocity gradients and the ice flux divergence are smoothed, the MAE becomes significantly smaller (Fig. 14). The MAE is now equal to $0.39 \mathrm{~m}$ i.e. $\mathrm{yr}^{-1}$.

Another observation standing out is that concerning Vadret Pers, the MAE mostly decreases when the ice flux divergence is smoothed, while for Vadret da Morteratsch, smoothing the gradients has a larger impact (see Fig. 14). Our explanation for these peculiar differences is that the gradients (both in terms of ice thickness and surface velocity) for Vadret Pers are already significantly smaller compared to those of Vadret da Morteratsch. The latter glacier has both a higher velocity and a larger ice thickness. Consequently, smoothing of the gradients for Vadret da Morteratsch is more decisive, whereas for Vadret Pers it is the other way around.

Other filters such as a mean filter or a Gaussian filter were explored, but all gave (slightly) less accurate results. However, our tests with a Gaussian filter showed only slightly larger errors for similar spatial scales. A Gaussian filter could therefore be a possible alternative to the exponential filter. Furthermore, the stakes used for validation were not entirely homogeneously distributed throughout the study area. The accuracy analysis may therefore have been biased towards these locations, which may also have influenced the choice of the optimal filter (length).

\section{Transferability of the method}

Our study shows that with the continuity equation method, the SMB at the position of the stakes can be accurately estimated. It therefore seems to be a promising method for supplementing SMB stake measurements on glaciers. To convert the results presented here to the conventional unit of mass balance, assumptions must be made for density. In the ablation area, to which our study area was limited, the SMB could have been converted directly to metres of water equivalent using an average ice density such as $900 \mathrm{~kg} \mathrm{~m}^{-3}$. However, if the presented method is applied to, for example, the accumulation area, specific attention is required for each quantity of the continuity equation (Miles et al., 2021).

The applicability of the method to other, less well-studied glaciers depends on how closely the elevation changes, the surface velocities and the ice thickness can be estimated for these ice bodies. In recent years, a new series of methods have arisen from which surface elevation changes and surface velocities can be rather accurately derived over glaciers (Brun et al., 2017; Paul et al., 2017; Braun et al., 2019; Nagy et al., 2019; Dussaillant et al., 2019; Sommer et al., 2020). This seems encouraging to investigate the applicability using satellite data with a resolution which should preferably 

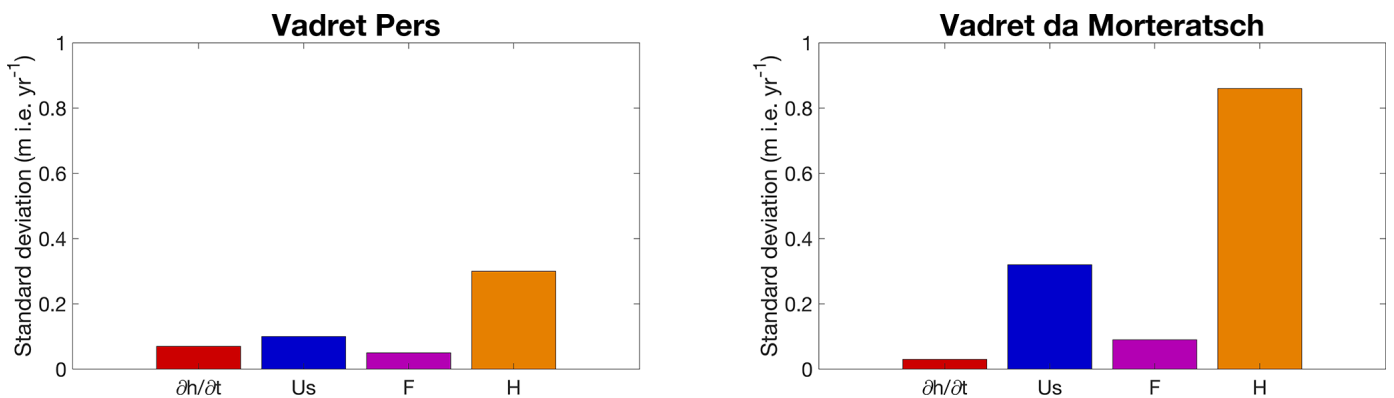

Figure 13. Standard deviation of the MAE for the perturbed versions of the surface elevation changes, the surface velocity $\left(u_{\mathrm{S}}\right)$, the $F$ value and the ice thickness $(H)$.
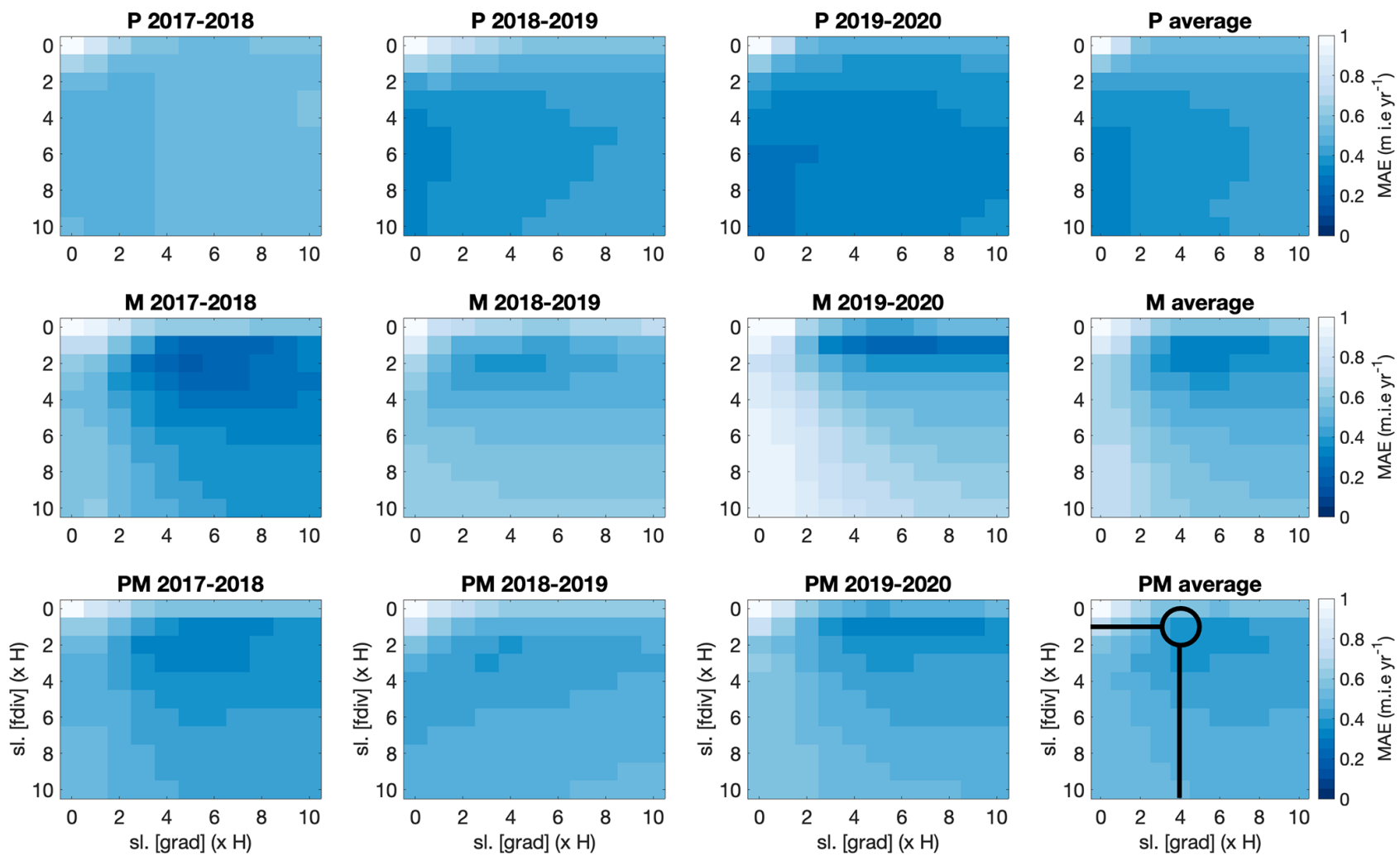

Figure 14. Mean absolute error between measured and modelled SMB for various scaling lengths. The scaling length depends on the local ice thickness $(\times H)$. Smoothing of the ice thickness and velocity gradients (grad) and smoothing of the ice flux divergence (fdiv) are represented by the horizontal axis and vertical axis, respectively. M represents Vadret da Morteratsch, P represents Vadret Pers, and PM represents the entire glacier complex. The plots entitled "average" concern the average over all balance years. The selected combination with which the ice flux divergence is calculated as shown in Fig. 9 is encircled with black.

be smaller than $10 \mathrm{~m}$ for accurate velocity determination. However, our analysis also showed that especially the ice thickness should be well known. So far, the ice thickness has only been measured for less than $0.5 \%$ of all glaciers on Earth (Gärtner-Roer et al., 2014). As shown in a recent study on four Central Asian glaciers, large-scale thickness estimates may capture the general pattern of the ice thickness distribution and total volume well yet exhibit significant deviations at the local scale (Van Tricht et al., 2021). To apply the proposed method on glaciers where the ice thickness has not been measured, estimated ice thicknesses such as the consensus estimate might seem to be a viable option (Farinotti et al., 2019). To evaluate the use of the consensus estimate, we also computed the SMB using our method and the consensus estimate for our optimal settings. Concerning Vadret Pers, the MAE and SEE were quite similar $(0.52$ and $0.62 \mathrm{~m}$ i.e. $\mathrm{yr}^{-1}$, respectively), while for Vadret da Morteratsch, the MAE and SEE were considerably higher (1.08 
and $1.22 \mathrm{~m}$ i.e. $\mathrm{yr}^{-1}$, respectively). The latter is likely the result of the ice thickness being significantly too small in the consensus estimate (maximally $223 \mathrm{~m}$, while we measured $297 \mathrm{~m}$ in 2020). This leaves the question open of whether the method can be applied to glaciers where the ice thickness is not measured or well known. Further testing could be performed on other glaciers for which multiannual highresolution topographic data already exist from repeated UAV surveys (e.g. Immerzeel et al., 2014; Kraaijenbrink et al., 2016; Wigmore et al., 2017; Benoit et al., 2019; Groos et al., 2019; Yang et al., 2020; Vincent et al., 2021).

\section{Conclusions}

In this study, a method was presented to estimate the surface mass balance pattern from UAV observations, a field with an ice thickness distribution and the principles of mass continuity. Annual surface elevation changes and surface velocities were quantified from UAV data and were shown to have very high accuracy. The method was applied to the entire ablation zone of Vadret da Morteratsch and Vadret Pers (Switzerland) for 3 individual balance years between 2017 and 2020. For the well-studied Morteratsch-Pers glacier complex, we were able to closely reproduce SMB surveyed at 16 stake locations. A major advantage of using close-range (UAV) remote sensing data is that a significantly more detailed SMB pattern can be obtained over the entire ablation area at a high spatial resolution, which is not feasible with a (small) number of stakes. This avoids the need for interpolation and extrapolations from a limited number of stakes, which can introduce several significant errors when the heterogeneity of the glacier surface cannot be captured well from the installed stake positions.

The analysis did not demonstrate a simple consensus on how to consider the ice flux divergence for optimal results on both glaciers. It proved to be necessary to consider large spatial scales concerning the ice flux divergence to apply the continuity equation method and closely reproduce the SMB at the position of ablation stakes. By using an exponential decay filter on the ice thickness and velocity gradients as well as the ensuing ice flux divergence over several times the local ice thickness (at least $2 \times$ ), the mean absolute error between modelled and measured SMB decreased to 0.25 $0.61 \mathrm{~m}$ i.e. $\mathrm{yr}^{-1}$ for the 3 balance years. Considering the uncertainty in the data and the stake measurements themselves, this is quite accurate. Our study therefore offers a transferable method that can be used, as long as the ice thickness is sufficiently well known, to estimate the SMB pattern from UAV data. With the increasing resolution of satellite data, we are convinced that the method presented here for UAV data will eventually yield similar accuracy for satellite data as well, allowing it to be easily transferred to other glaciers and regions.
Code and data availability. The model code written in MATLAB, which was used as the basis for this research, can be found and downloaded from https://doi.org/10.5281/zenodo.5501305 (Van Tricht, 2021). The other input datasets, the SMB data and the UAVcreated DSMs will be provided on request by Lander Van Tricht.

Author contributions. LVT developed the method, performed the experiments and wrote the manuscript. $\mathrm{PH}$ provided guidance in implementing the research and interpreting the results and assisted during the entire process. JVB and AV contributed to the fieldwork, collaborated in developing the method and improved the manuscript throughout the entire process. KVO assisted during the fieldwork and introduced LVT in using UAVs for research purposes. HZ participated in the fieldwork for many years and contributed throughout the entire process to developing the method and optimising and refining the research.

Competing interests. The authors declare that they have no conflict of interest.

Disclaimer. Publisher's note: Copernicus Publications remains neutral with regard to jurisdictional claims in published maps and institutional affiliations.

Acknowledgements. The authors would like to thank Chloe Marie Paice, Felix Vanderleenen, He Zhang, Robbe Neyns, Steven De Hertog, Veronica Tollenaar and Yoni Verhaegen, who assisted during the fieldwork in performing stake measurements and distributing and collecting GCPs. We also want to thank Alexander Raphael Groos for his constructive comments on the manuscript.

Financial support. Lander Van Tricht holds a PhD fellowship of the Research Foundation - Flanders (FWO-Vlaanderen) and is affiliated with the Vrije Universiteit Brussel (VUB). Harry Zekollari contributed to the fieldwork as a PhD fellow of the Research Foundation - Flanders (FWO-Vlaanderen) and at a later stage as a Marie Skłodowska-Curie fellow at the TU Delft (grant no. 799904). Kristof Van Oost is an FNRS research director.

Review statement. This paper was edited by Etienne Berthier and reviewed by Evan Miles and one anonymous referee.

\section{References}

Anderson, L. S. and Anderson, R. S.: Modeling debris-covered glaciers: response to steady debris deposition, The Cryosphere, 10, 1105-1124, https://doi.org/10.5194/tc-10-1105-2016, 2016.

Benoit, L., Gourdon, A., Vallat, R., Irarrazaval, I., Gravey, M., Lehmann, B., Prasicek, G., Gräff, D., Herman, F., and Mariethoz, G.: A high-resolution image time series of the Gorner 
Glacier - Swiss Alps - derived from repeated unmanned aerial vehicle surveys, Earth Syst. Sci. Data, 11, 579-588, https://doi.org/10.5194/essd-11-579-2019, 2019.

Berthier, E. and Vincent, C.: Relative contribution of surface massbalance and ice-flux changes to the accelerated thinning of Mer de Glace, French Alps, over 1979-2008, J. Glaciol., 58, 501-512, https://doi.org/10.3189/2012JoG11J083, 2012.

Bisset, R. R., Dehecq, A., Goldberg, D. N., Huss, M., Bingham, R. G., and Gourmelen, N.: Reversed Surface-MassBalance Gradients on Himalayan Debris-Covered Glaciers Inferred from Remote Sensing, Remote Sensing, 12, https://doi.org/10.3390/rs12101563, 2020.

Braithwaite, R. J.: Glacier mass balance: the first 50 years of international monitoring, Prog. Phys. Geogr., 26, 76-95, https://doi.org/10.1191/0309133302pp326ra, 2002.

Braun, M. H., Malz, P., Sommer, C., Farías-Barahona, D., Sauter, T., Casassa, G., Soruco, A., Skvarca, P., and Seehaus, T. C.: Constraining glacier elevation and mass changes in South America, Nat. Clim. Change, 9, 130-136, https://doi.org/10.1038/s41558018-0375-7, 2019,

Brun, F., Berthier, E., Wagnon, P., Kääb, A., and Treichler, D.: A spatially resolved estimate of High Mountain Asia glacier mass balances from 2000 to 2016, Nat. Geosci., 10, 668-673, https://doi.org/10.1038/ngeo2999, 2017.

Brun, F., Wagnon, P., Berthier, E., Shea, J. M., Immerzeel, W. W., Kraaijenbrink, P. D. A., Vincent, C., Reverchon, C., Shrestha, D., and Arnaud, Y.: Ice cliff contribution to the tongue-wide ablation of Changri Nup Glacier, Nepal, central Himalaya, The Cryosphere, 12, 3439-3457, https://doi.org/10.5194/tc-12-34392018, 2018.

Davaze, L., Rabatel, A., Dufour, A., Hugonnet, R., and Arnaud, Y.: Region-Wide Annual Glacier Surface Mass Balance for the European Alps From 2000 to 2016, Front. Earth Sci., 8, 0-14, https://doi.org/10.3389/feart.2020.00149, 2020.

Dussaillant, I., Berthier, E., Brun, F., Masiokas, M., Hugonnet, R., Favier, V., Rabatel, A., Pitte, P., and Ruiz, L.: Two decades of glacier mass loss along the Andes, Nat. Geosci., 12, 802-808, https://doi.org/10.1038/s41561-019-0432-5, 2019.

Farinotti, D., Huss, M., Fürst, J. J., Landmann, J., Machguth, H., Maussion, F., and Pandit, A.: A consensus estimate for the ice thickness distribution of all glaciers on Earth, Nat. Geosci., 12, 168-173, https://doi.org/10.1038/s41561-019-0300-3, 2019.

Fischer, M., Huss, M., and Hoelzle, M.: Surface elevation and mass changes of all Swiss glaciers 1980-2010, The Cryosphere, 9, 525-540, https://doi.org/10.5194/tc-9-525-2015, 2015.

Gärtner-Roer, I., Naegeli, K., Huss, M., Knecht, T., Machguth, H., and Zemp, M.: A database of worldwide glacier thickness observations, Global Planet. Change, 122, 330-344, https://doi.org/10.1016/j.gloplacha.2014.09.003, 2014.

Gindraux, S., Boesch, R., and Farinotti, D.: Accuracy Assessment of Digital Surface Models from Unmanned Aerial Vehicles' Imagery on Glaciers, Remote Sensing, 9, 186, https://doi.org/10.3390/rs9020186, 2017.

Goldstein, E. B., Oliver, A. R., deVries, E., Moore, L. J., and Jass, T.: Ground control point requirements for structure-from-motion derived topography in lowslope coastal environments, PeerJPrePrints, 3, e1444v1, https://doi.org/10.7287/peerj.preprints.1444v1, 2015.
Groos, A. R., Bertschinger, T. J., Kummer, C. M., Erlwein, S., Munz, L., and Philipp, A.: The Potential of Low-Cost UAVs and Open-Source Photogrammetry Software for HighResolution Monitoring of Alpine Glaciers: A Case Study from the Kanderfirn (Swiss Alps), Geosciences, 9, 1-21, https://doi.org/10.3390/geosciences9080356, 2019.

Gudmundsson, G. H. and Bauder, A.: Towards an Indirect Determination of the Mass-balance Distribution of Glaciers using the Kinematic Boundary Condition, Geogr. Ann., 81, 575-583, https://doi.org/10.1111/1468-0459.00085, 1999.

Heid, T. and Kääb, A.: Evaluation of existing image matching methods for deriving glacier surface displacements globally from optical satellite imagery, Remote Sens. Environ., 118, 339-355, https://doi.org/10.1016/j.rse.2011.11.024, 2012.

Hubbard, A., Willis, I., Sharp, M., Mair, D., Nienow, P., Hubbard, B., and Blatter, H.: Glacier mass-balance determination by remote sensing and high-resolution modelling, J. Glaciol., 46, 491498, https://doi.org/10.3189/172756500781833016, 2000.

Huss, M., Dhulst, L., and Bauder, A.: New long-term massbalance series for the Swiss Alps, J. Glaciol., 61, 551-562, https://doi.org/10.3189/2015JoG15J015, 2015.

Hutter, R. K. and Morland, L. W.: Euromech colloquium 172: Mechanics of glaciers, Interlaken, 19-23 September 1983, Cold Reg. Sci. Technol., 9, 77-86, https://doi.org/10.1016/0165232X(84)90049-1, 1984.

Immerzeel, W. W., Kraaijenbrink, P. D. A., Shea, J. M., Shrestha, A. B., Pellicciotti, F., Bierkens, M. F. P., and de Jong, S. M. High-resolution monitoring of Himalayan glacier dynamics using unmanned aerial vehicles, Remote Sens. Environ., 150, 93103, https://doi.org/10.1016/j.rse.2014.04.025, 2014.

Kääb, A. and Funk, M.: Modelling mass balance using photogrammetric and geophysical data: a pilot Study at Griesgletscher, Swiss Alps, J. Glaciol., 45, 575-583, https://doi.org/10.3189/S0022143000001453, 1999.

Kamb, B. and Echelmeyer, K. A.: Stress-gradient Coupling in Glacier Flow: IV. Effects of the "T" Term, J. Glaciol., 32, 342349, https://doi.org/10.3189/S0022143000012016, 1986.

Kaser, G., Fountain, A., and Jansson, P.: A manual for monitoring the mass balance of mountain glaciers, International Hydrological Programme, IHP-VI. Technical Documents in Hydrology 59, UNESCO, Paris, 2003.

Kienholz, C., Pierce, J., Hood, E., Amundson, J. M., Wolken, G. J., Jacobs, A., Hart, S., Wikstrom, Jones K., AbdelFattah, D., Johnson, C., and Conaway, J. S.: Deglacierization of a Marginal Basin and Implications for Outburst Floods, Mendenhall Glacier, Alaska, Front. Earth Sci., 8, 1-21, https://doi.org/10.3389/feart.2020.00137, 2020.

Kraaijenbrink, P., Meijer, S. W., Shea, J. M., Pellicciotti, F., De Jong, S. M., and Immerzeel, W. W.: Seasonal surface velocities of a Himalayan glacier derived by automated correlation of unmanned aerial vehicle imagery, Ann. Glaciol., 57, 103-113, https://doi.org/10.3189/2016AoG71A072, 2016.

Langhammer, L., Grab, M., Bauder, A., and Maurer, H.: Glacier thickness estimations of alpine glaciers using data and modeling constraints, The Cryosphere, 13, 2189-2202, https://doi.org/10.5194/tc-13-2189-2019, 2019.

Le Brocq, A. M., Payne, A. J., and Siegert, M. J.: West Antarctic balance calculations: Impact of flux-routing algorithm, smooth- 
ing algorithm and topography, Comput. Geosci., 32, 1780-1795, https://doi.org/10.1016/j.cageo.2006.05.003, 2006.

Long, N., Millescamps, B., Pouget, F., Dumon, A., Lachaussée, N., and Bertin, X.: Accuracy assessment of coastal topography derived from UAV images, The International Archives of the Photogrammetry, Remote Sensing and Spatial Information Sciences, XLI-B1, 1127-1134, https://doi.org/10.5194/isprsarchives-XLI-B1-1127-2016, 2016.

Marzeion, B., Hock, R., Anderson, B., Bliss, A., Champollion, N., Fujita, K., Huss, M., Immerzeel, W. W., Kraaijenbrink, P., Malles, J., Maussion, F., Radić, V., Rounce, D. R., Sakai, A., Shannon, S., Wal, R., and Zekollari, H.: Partitioning the Uncertainty of Ensemble Projections of Global Glacier Mass Change, Earth's Future, 8, 1-25, https://doi.org/10.1029/2019EF001470, 2020.

Messerli, A. and Grinsted, A.: Image georectification and feature tracking toolbox: ImGRAFT, Geosci. Instrum. Method. Data Syst., 4, 23-34, https://doi.org/10.5194/gi-4-23-2015, 2015.

Miles, E., McCarthy, M., Dehecq, A., Kneib, M., Fugger, S., and Pellicciotti, F.: Health and sustainability of glaciers in High Mountain Asia, Nat. Commun., 12, 2868, https://doi.org/10.1038/s41467-021-23073-4, 2021.

Nagy, T., Andreassen, L. M., Duller, R. A., and Gonzalez, P. J.: SenDiT: The Sentinel-2 Displacement Toolbox with Application to Glacier Surface Velocities, Remote Sensing, 11, 1151, https://doi.org/10.3390/rs11101151, 2019.

Nemec, J., Huybrechts, P., Rybak, O., and Oerlemans, J.: Reconstruction of the annual balance of Vadret da Morteratsch, Switzerland, since 1865, Ann. Glaciol., 50, 126-134, https://doi.org/10.3189/172756409787769609, 2009.

Nuimura, T., Fujita, K., Fukui, K., Asahi, K., Aryal, R., and Ageta, Y.: Temporal Changes in Elevation of the DebrisCovered Ablation Area of Khumbu Glacier in the Nepal Himalaya since 1978, Arct. Antarct. Alp. Res., 43, 246-255, https://doi.org/10.1657/1938-4246-43.2.246, 2011.

Paul, F., Bolch, T., Briggs, K., Kääb, A., McMillan, M., McNabb, R., Nagler, T., Nuth, C., Rastner, P., Strozzi, T., and Wuite, J.: Error sources and guidelines for quality assessment of glacier area, elevation change, and velocity products derived from satellite data in the Glaciers_cci project, Remote Sens. Environ., 203, 256-275, https://doi.org/10.1016/j.rse.2017.08.038, 2017.

Reeh, N., Mohr, J. J., Krabill, W. B., Thomas, R., Oerter, H., Gundestrup, N., and Bøggild, C. E.: Glacier specific ablation rate derived by remote sensing measurements, Geophys. Res. Lett., 29, 10-1-10-4, https://doi.org/10.1029/2002GL015307, 2002.

Reeh, N., Mohr, J. J,. Madsen, S. N., Oerter, H., and Gundestrup, N. S.: Three-dimensional surface velocities of Storstrømmen glacier, Greenland, derived from radar interferometry and ice-sounding radar measurements, J. Glaciol., 49, 201-209, https://doi.org/10.3189/172756503781830818, 2003.

Reznichenko, N., Davies, T., Shulmeister, J., and McSaveney, M.: Effects of debris on ice-surface melting rates: an experimental study, J. Glaciol., 56, 384-394, https://doi.org/10.3189/002214310792447725, 2010.

Rossini, M., Di Mauro, B., Garzonio, R., Baccolo, G., Cavallini, G., Mattavelli, M., De Amicis, M., and Colombo, R.: Rapid Melting Dynamics of an Alpine Glacier with Repeated UAV Photogrammetry, Geomorphology, 304, 159-172, https://doi.org/10.1016/j.geomorph.2017.12.039, 2018.
Rounce, D. R., King, O., McCarthy, M., Shean, D. E., and Salerno, F.: Quantifying Debris Thickness of Debris- Covered Glaciers in the Everest Region of Nepal Through Inversion of a Subdebris Melt Model, J. Geophys. Res. Earth Surf., 123, 1094-1115, https://doi.org/10.1029/2017JF004395, 2018.

Ruiz, L., Berthier, E., Masiokas, M., Pitte, P., and Villalba, R.: First surface velocity maps for glaciers of Monte Tronador, North Patagonian Andes, derived from sequential Pléiades satellite images, J. Glaciol., 61, 908-922, https://doi.org/10.3189/2015JoG14J134, 2015.

Ryan, J. C., Hubbard, A. L., Box, J. E., Todd, J., Christoffersen, P., Carr, J. R., Holt, T. O., and Snooke, N.: UAV photogrammetry and structure from motion to assess calving dynamics at Store Glacier, a large outlet draining the Greenland ice sheet, The Cryosphere, 9, 1-11, https://doi.org/10.5194/tc-9-1-2015, 2015.

Seroussi, H., Morlighem, M., Rignot, E., Larour, E., Aubry, D., Ben Dhia, H., and Kristensen, S. S.: Ice flux divergence anomalies on 79north Glacier, Greenland, Geophys. Res. Lett., 38, L09501, https://doi.org/10.1029/2011GL047338, 2011.

Sommer, C., Malz, P., Seehaus, T. C., Lippl, S., Zemp, M., and Braun, M. H.: Rapid glacier retreat and downwasting throughout the European Alps in the early 21st century, Nat. Commun., 11, 3209, https://doi.org/10.1038/s41467-020-16818-0, 2020.

Tahar, K. N., Ahmad, A., Aziz, W. A., Akib, W. M., Mohd, W., and Mohd, N. W.: Assessment on Ground Control Points in Unmanned Aerial System Image Processing for Slope Mapping Studies, Int. J. Sci. Eng. Res., 3, 1-10, 2012.

Tonkin, T. and Midgley, N.: Ground-Control Networks for Image Based Surfac Reconstruction: An Investigation of Optimum Survey Designs Using UAV Derived Imagery and Structure-from-Motion Photogrammetry, Remote Sensing, 8, 786, https://doi.org/10.3390/rs8090786, 2016.

Van Tricht, L.: LanderVT/SMB-from-UAV: SMB from UAV (v2.0), Zenodo [data set], https://doi.org/10.5281/zenodo.5501305, 2021.

Van Tricht, L., Huybrechts, P., Van Breedam, J., Fürst, J. J., Rybak, O., Satylkanov, R., Ermenbaiev, B., Popovnin, V., Neyns, R., Paice, C. M., and Malz, P.: Measuring and inferring the ice thickness distribution of four glaciers in the Tien Shan, Kyrgyzstan, J. Glaciol., 67, 269-286, https://doi.org/10.1017/jog.2020.104, 2021.

van Woerkom, T., Steiner, J. F., Kraaijenbrink, P. D. A., Miles, E. S., and Immerzeel, W. W.: Sediment supply from lateral moraines to a debris-covered glacier in the Himalaya, Earth Surf. Dynam., 7, 411-427, https://doi.org/10.5194/esurf-7-411-2019, 2019.

Verhaegen, Y., Huybrechts, P., Rybak, O., and Popovnin, V. V.: Modelling the evolution of Djankuat Glacier, North Caucasus, from 1752 until 2100 CE, The Cryosphere, 14, 4039-4061, https://doi.org/10.5194/tc-14-4039-2020, 2020.

Vincent, C., Wagnon, P., Shea, J. M., Immerzeel, W. W., Kraaijenbrink, P., Shrestha, D., Soruco, A., Arnaud, Y., Brun, F., Berthier, E., and Sherpa, S. F.: Reduced melt on debris-covered glaciers: investigations from Changri Nup Glacier, Nepal, The Cryosphere, 10, 1845-1858, https://doi.org/10.5194/tc-10-18452016, 2016.

Vincent, C., Cusicanqui, D., Jourdain, B., Laarman, O., Six, D., Gilbert, A., Walpersdorf, A., Rabatel, A., Piard, L., Gimbert, F., Gagliardini, O., Peyaud, V., Arnaud, L., Thibert, E., Brun, F., and Nanni, U.: Geodetic point surface mass balances: a new ap- 
proach to determine point surface mass balances on glaciers from remote sensing measurements, The Cryosphere, 15, 1259-1276, https://doi.org/10.5194/tc-15-1259-2021, 2021.

Wagnon, P., Brun, F., Khadka, A., Berthier, E., Shrestha, D., Vincent, C., Arnaud, Y., Six, D., Dehecq, A., Ménégoz, M., and Jomelli, V.: Reanalysing the 2007-19 glaciological mass-balance series of Mera Glacier, Nepal, Central Himalaya, using geodetic mass balance, J. Glaciol., 67, 117-125, https://doi.org/10.1017/jog.2020.88, 2021.

Whitehead, K., Moorman, B. J., and Hugenholtz, C. H.: Brief Communication: Low-cost, on-demand aerial photogrammetry for glaciological measurement, The Cryosphere, 7, 1879-1884, https://doi.org/10.5194/tc-7-1879-2013, 2013.

Wigmore, O. and Mark, B.: Monitoring tropical debris-covered glacier dynamics from high-resolution unmanned aerial vehicle photogrammetry, Cordillera Blanca, Peru, The Cryosphere, 11, 2463-2480, https://doi.org/10.5194/tc-11-2463-2017, 2017.

Wouters, B., Gardner, A. S., and Moholdt, G.: Global Glacier Mass Loss During the GRACE Satellite Mission (2002-2016), Front. Earth Sci., 7, 1-11, https://doi.org/10.3389/feart.2019.00096, 2019.

Yang, W., Zhao, C., Westoby, M., Yao, T., Wang, Y., Pellicciotti, F., Zhou, J., He, Z., and Miles, E.: Seasonal Dynamics of a Temperate Tibetan Glacier Revealed by High-Resolution UAV Photogrammetry and In Situ Measurements, Remote Sensing, 12, 2389, https://doi.org/10.3390/rs12152389, 2020.

Zekollari, H. and Huybrechts, P.: On the climate-geometry imbalance, response time and volume-area scaling of an alpine glacier: insights from a 3-D flow model applied to Vadret da Morteratsch, Switzerland, Ann. Glaciol., 56, 51-62, https://doi.org/10.3189/2015AoG70A921, 2015.
Zekollari, H. and Huybrechts, P.: Statistical modelling of the surface mass-balance variability of the Morteratsch glacier, Switzerland: strong control of early melting season meteorological conditions, J. Glaciol., 64, 275-288, https://doi.org/10.1017/jog.2018.18, 2018.

Zekollari, H., Huybrechts, P., Fürst, J. J., Rybak, O., and Eisen, O. Calibration of a higher-order 3-D ice-flow model of the Morteratsch glacier complex, Engadin, Switzerland, Ann. Glaciol., 54, 343-351, https://doi.org/10.3189/2013AoG63A434, 2013.

Zekollari, H., Fürst, J. J., and Huybrechts, P.: Modelling the evolution of Vadret da Morteratsch, Switzerland, since the Little Ice Age and into the future, J. Glaciol., 60, 1155-1168, https://doi.org/10.3189/2014JoG14J053, 2014.

Zemp, M., Thibert, E., Huss, M., Stumm, D., Rolstad Denby, C., Nuth, C., Nussbaumer, S. U., Moholdt, G., Mercer, A., Mayer, C., Joerg, P. C., Jansson, P., Hynek, B., Fischer, A., Escher-Vetter, H., Elvehøy, H., and Andreassen, L. M.: Reanalysing glacier mass balance measurement series, The Cryosphere, 7, 1227 1245, https://doi.org/10.5194/tc-7-1227-2013, 2013.

Zemp, M., Huss, M., Thibert, E., Eckert, N., McNabb, R., Huber, J., Barandun, M., Machguth, H., Nussbaumer, S.U., GärtnerRoer, I., Thomson, L., Paul, F., Maussion, F., Kutuzov, S., and Cogley, J. G.: Global glacier mass changes and their contributions to sea-level rise from 1961 to 2016, Nature, 568, 382-386, https://doi.org/10.1038/s41586-019-1071-0, 2019.

Zhang, H., Aldana-Jague, E., Clapuyt, F., Wilken, F., Vanacker, V., and Van Oost, K.: Evaluating the potential of post-processing kinematic (PPK) georeferencing for UAV-based structure-frommotion (SfM) photogrammetry and surface change detection, Earth Surf. Dynam., 7, 807-827, https://doi.org/10.5194/esurf7-807-2019, 2019. 